\title{
DETAILING OF PRESTRESSED CONCRETE PILES FOR DUCTILITY
}

\author{
R. Park ${ }^{(i)}$, M. J. N. Priestley(ii), T. J. Falconer ${ }^{(i i i)}$, Pam Hoat Joen ${ }^{(i v)}$
}

SYNOPSIS

The role of spiral reinforcement in improving the ductility of concrete and the background to the New Zealand concrete design code equations for spiral reinforcement in potential plastic hinge zones are outlined. Tests and analysis of eleven full scale pretensioned prestressed concrete piles with a $400 \mathrm{~mm}$ octagonal cross section are reported. The tests were to determine the available ductility of the piles when subjected to large inelastic cyclic deformations from lateral loading which simulated severe seismic loading. The main variables of the tests were the amount of longitudinal nonprestressed reinforcement present, the applied axial load level, the amount of transverse spiral reinforcement present and the use of either Grade 275 or hard drawn spiral steel. The results showed that when the code specified quantity of spiral steel was present the piles were capable of undergoing very large post-elastic deformations when subjected to cyclic lateral loading without significant loss in load carrying ability. Piles with about $50 \%$ of the code specified quantity of spiral reinforcement were capable of reaching displacement ductility factors of at least \pm 4 providing the spiral spacing did not exceed about 4 tendon diameters. When the spiral reinforcement was provided by hard drawn wire the pile response was eventually limited by the fracture of the confining steel reinforcement, whereas piles with Grade 275 steel spirals did not suffer confining steel fracture.

\section{KEY WORDS}

Detailing, ductility, earthquake resistance, piles, prestressed concrete, spiral reinforcement.

\section{LIST OF SYMBOLS}

$A_{C}=$ area of concrete core measured to outside of spiral

$\mathrm{A}_{\mathrm{g}}=$ gross area of concrete section

$\mathrm{A}_{\mathrm{pt}}=$ total area of prestressing strand

$A_{p s}=$ area of spiral bar

$A_{\text {st }}=$ total area of longitudinal nonprestressed reinforcement

$\mathrm{d}_{\mathrm{b}}=$ diameter of prestressing tendon or reinforcing bar

$d_{s}=$ diameter of spiral (out-to-out)

$\mathrm{D}=$ pile diameter

$\mathrm{f}_{\mathrm{C}}=$ concrete compressive stress

$\mathrm{f}_{\mathrm{C}}^{\prime}=$ compressive cylinder strength of (unconfined) concrete

(i) Professor and Head of Civil Engineering, University of Canterbury, New Zealand.

(ii) Reader in Civil Engineering, University of Canterbury, New Zealand.

(iii) Assistant Engineer, Hamilton City Council, Hamilton, New Zealand.

(iv) Graduate Student, Department of Civil Engineering, University of C'anterbury, New Zealand.

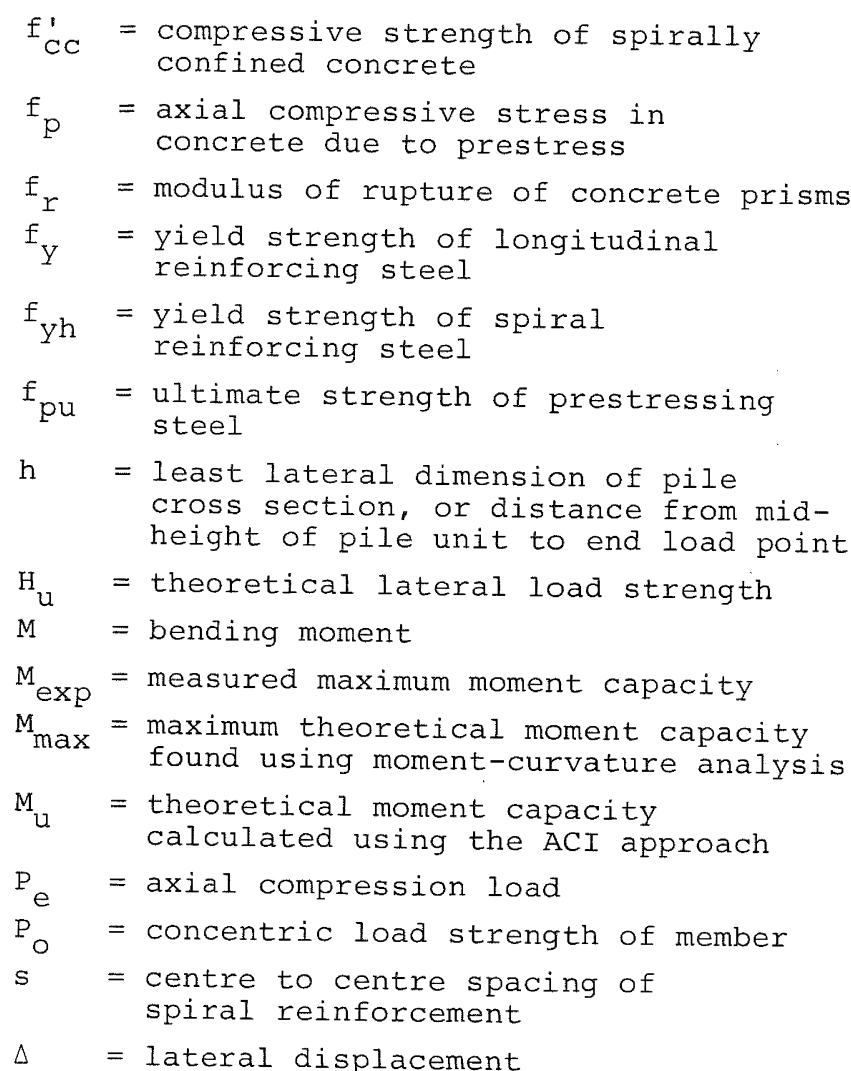




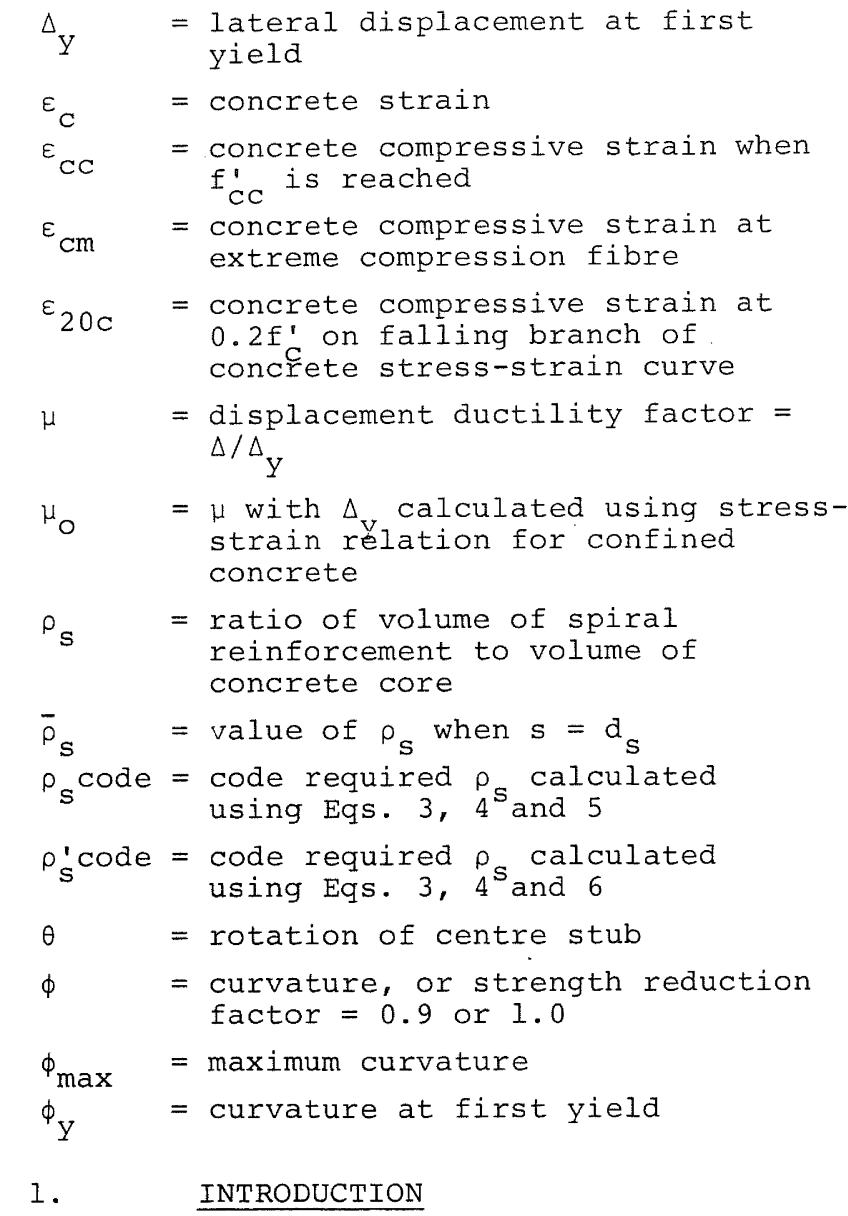

Piles in soft soils supporting building or bridge structures can be subjected to large horizontal displacements when subjected to severe earthquakes. The resulting deformations can result in significant curvatures in some regions of the pile. One region of high curvature is at the pile-pile cap interface, due to the end fixity of the pile in the pile cap. A second region of high curvature is within the soil. These critical regions are illustrated in Fig. 1. In piles embedded in layers of soil, with soil modulus varying down the depth, the pile curvature may be particularly high at the interface between hard and soft layers of soil.

Severe damage to piles has been observed during some earthquakes. For example, earthquake damage to piles due to large imposed curvatures has been described by Sheppard (1) and Gerwick (2) .

The regions of the pile where high curvatures occur need to be designed to possess adequate ductility, where ductility may be defined as the ability to undergo large amplitude cyclic deformations in the inelastic range without substantial reduction in strength. The main factor affecting the ductility of structural concrete compression members has been shown (3) to be the quantity of transverse reinforcement in the member. Sufficient transverse hoop or spiral reinforcement must be present to confine the compressed concrete so that it is capable of carrying stress at high compressive strains, to prevent the buckling of compressed reinforcing bars and tendons at large deformations, and to provide adequate shear resistance. The use of spiral or circular hoop reinforcement is a more efficient means of ensuring ductility than the use of arrangements of rectangular hoops (3).

In New Zealand concern has been expressed about the ability of prestressed piles in foundations to cope adequately with possible curvature demands that could arise during severe earthquake attack. For bridge foundations it has been the policy of the New Zealand Ministry of Works and Development to specify the presence of substantial non-prestressed longitudinal steel in prestressed concrete piles. As a result, other forms of piling, such as steel sections, concrete filled steel shell piles or reinforced concrete cylinders have been more economical to use, and have virtually supplanted the use of prestressed piling in bridge foundations.

The New Zealand concrete design code (4) contains provisions for detailing reinforced concrete columns for ductility, and for detailing reinforced, partially prestressed, and prestressed concrete members of framed structures for ductility. However, the detailing procedures for ductility for prestressed concrete piles are not specifically defined.

Sheppard (1) and Gerwick (2) have summarised the results of some lateral load tests on prestressed concrete piles carried out in California and list specific recommendations for spiral reinforcement requirements. The quantity of spiral steel with a yield strength of $414 \mathrm{MPa}$

recommended in critical regions of piles can be at least $\rho_{s}=0.02$, where $\rho$ is the ratio of the volume of spiral reinforcement to the volume of the concrete core.

It is evident that more tests are required on a range of prestressed and partially prestressed concrete piles, subjected to simulated seismic loading, to obtain a better understanding of behaviour and of the detailing procedures necessary to achieve ductile behaviour.

It should be noted that because of the difficulties associated with the repair of foundation damage occurring during severe earthquakes, it is desirable to design the piles so as to remain undamaged during severe earthquakes. Ideally, the design concept should aim at dissipating seismic energy by ductile yielding at plastic hinge regions in the structure above the foundations or in mechanical energy dissipating devices placed between the foundations and the structure. That is, the foundation should be provided with sufficient strength to ensure as far as possible that they remain in the elastic range while energy dissipation occurs at the chosen yielding locations elsewhere 


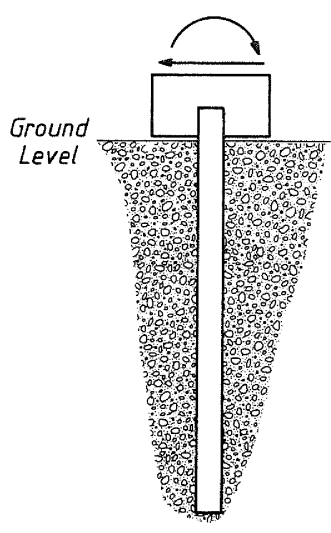

Pile and cap

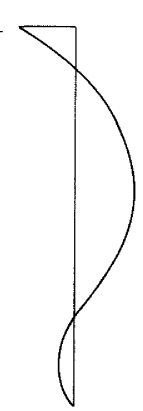

Bending

Moment

(a) Pile totally embedded in soil

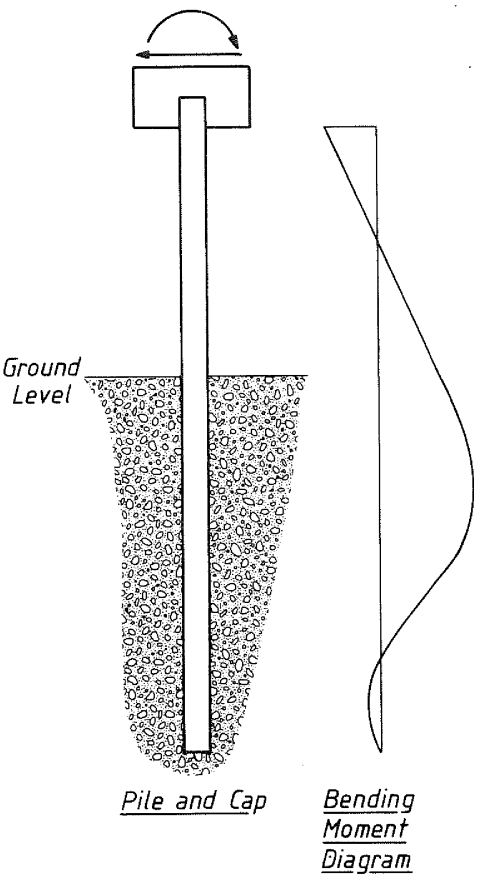

(b) Pile partially embedded in soil

Fig. I Bending of Long Piles Due to Horizontal Seismic Loading With Pile Cap Free to Translate But Not to Rotate
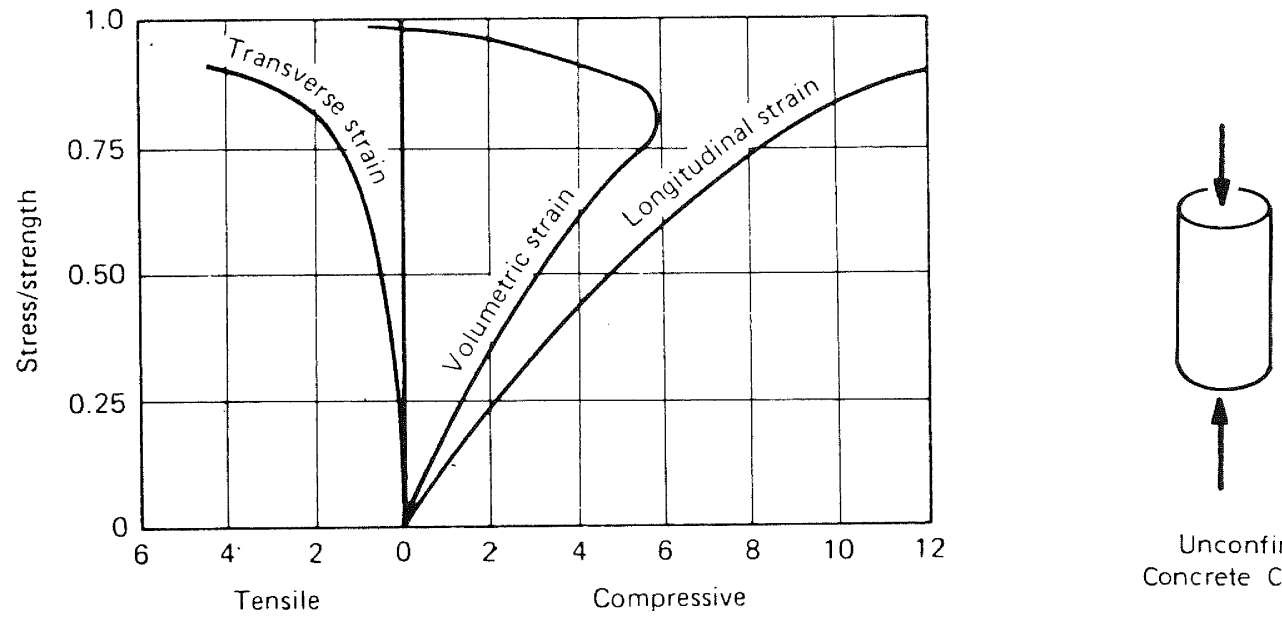

Unconfined Concrete Cylinder

Strains $\times 10^{-4}$

Fig. 2 Strains Measured on a Plain Concrete Cylinder Loaded Concentrically in Compression (3) 
during a severe earthquake. However, uncertainties do exist with regard to soilstructure interaction and the resulting actual pile behaviour during a severe earthquake, and it would appear to be essential to detail piles so as to be capable of a reasonable degree of ductile behaviour.

This paper outlines the role of spiral reinforcement in improving the ductility of concrete and discusses the recommendations of the New Zealand concrete design code NZS 3101 (4) for detailing potential plastic hinge regions of compression members. Then results are summarised from two recent research projects, involving analysis and tests conducted on eleven full scale pretensioned prestressed concrete piles subjected to compressive load and intense cycles of lateral loading which simulated severe seismic loading. The first project, by Falconer and Park $(5,6)$, concentrated on assessing the need for additional nonprestressed steel reinforcement for ductility and the general behaviour of fully confined piles under different levels of axial load, to determine the characteristics of prestressed piles where the formation of plastic hinges was permitted as part of the design philosophy. The second project, by Pam and Park (7) investigated the performance of prestressed piles with reduced quantities of confining reinforcement, and included piles where the confinement was provided by high strength drawn wire.

2 .

DUCTILITY OF SPIRALLY REINFORCED
CONCRETE

2.1

\section{Confinement of Concrete by Spiral Reinforcement}

Clearly the available ductility of structural concrete compression members is very dependent on the stress-strain relationship for the concrete. Unconfined concrete can be quite brittle, particularly if the concrete is of high strength.

Fig. 2 shows typical strains measured on an unconfined (plain) concrete cylinder loaded concentrically in compression. At low stresses the ratio between the transverse to longitudinal strains, referred to as Poisson's ratio, is in the range 0.15 to 0.25 . However at high compressive stresses the transverse strains increase rapidly, owing to the progressive internal cracking of the concrete. That is, during most of the loading range the volume of the concrete decreases but at high stresses near the compressive strength the transverse strains become so high that the volume of the concrete actually increases and the specimen, if unconfined, fails with splitting cracks in the direction parallel to the compressive loading.

If closed transverse reinforcement is present the concrete becomes confined when the transverse strains cause it to bear out against the transverse reinforcement. The resulting passive confining pressure applied by the transverse reinforcement can considerably improve the longitudinal stress-strain characteristics of concrete at higher strains.

Spirals or circular hoops, because of their shape, are in hoop tension and provide a continuous confining pressure around the circumference as illustrated in Fig. 3. Square or rectangular shaped hoops are less efficient since the sides tend to bend outwards and the confining pressure is only applied near the hoop corners.

The confinement of concrete is improved if the spirals or circular hoops are placed at relatively close spacing, as is illustrated in Fig. 4. Confinement between transverse bars is provided by arching of the concrete between the bars, and if the spacing of the transverse bars is small the arching of the concrete is more efficient since the arches are shallower and hence more of the concrete area is effectively confined.

Further variables influencing the confinement are the ratio of the volume of transverse reinforcement to the volume of the concrete core and the yield strength of the transverse reinforcement, since a high volumetric ratio and a high yield strength of transverse steel will both lead to higher confining pressure.

Outside the transverse reinforcement the concrete is not confined. The cover concrete will tend to spall after the unconfined strength is reached.

At far advanced longitudinal compressive strains the lateral pressure applied by the confined concrete to the transverse reinforcement can eventually be sufficient to cause the transverse reinforcement to fracture. The stage of first fracture of the transverse reinforcement can be regarded as the end of the useful region of the stress-strain curve of the confined concrete core, since the concrete then is no longer effectively confined.

Fig. 5 shows longitudinal stressstrain curves measured for the core concrete of concentrically loaded spirally reinforced columns tested by Mander, et al (8). The columns were $500 \mathrm{~mm}$ diameter by $1500 \mathrm{~mm}$ high. The concentric load was applied at a strain rate of 0.013 per second. Grade 275 spiral reinforcement was used. Four linear potentiometers, mounted on transverse steel rods embedded in the concrete, were used to measure longitudinal strains over a $450 \mathrm{~mm}$ gauge length in the central region of the column. The stress-strain curve for the confined core concrete was determined by subtracting from the total load carried at each strain increment the load carried by the cover concrete (assumed to act as unconfined concrete) and the load carried by the 


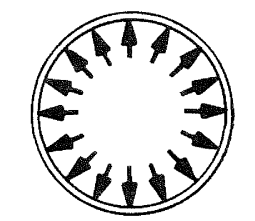

(a) Confinement from

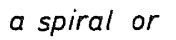

circular hoop

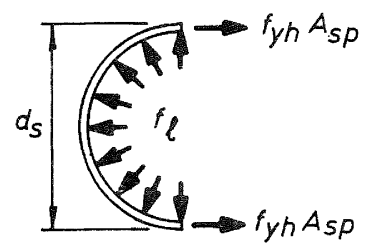

(b) Forces acting on one-half spiral or circular hoop

Fig. 3 Confinement of Concrete by Spirals or Circular Hoops

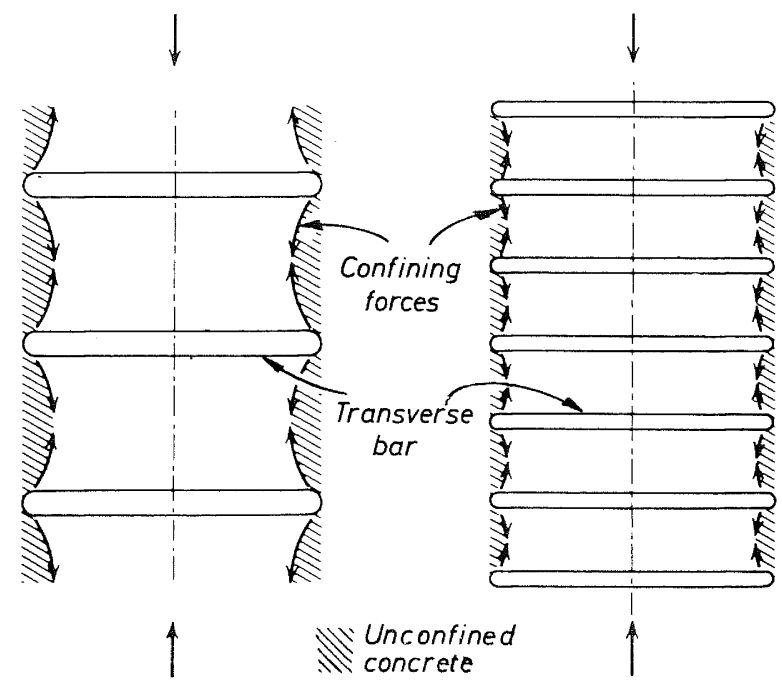

Fig. 4 Effect of Spacing of Spirals or Circular Hoops on Efficiency of Confinement

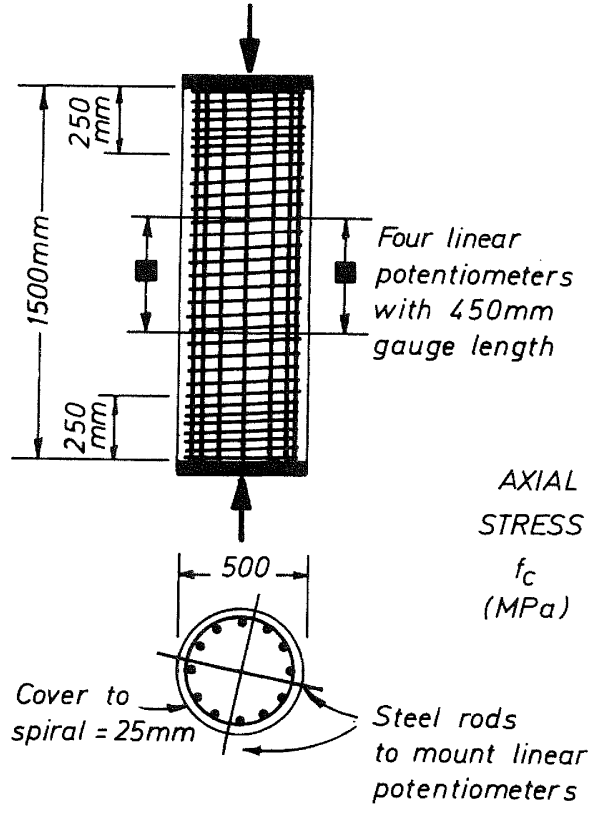

(a) Specimen dimensions

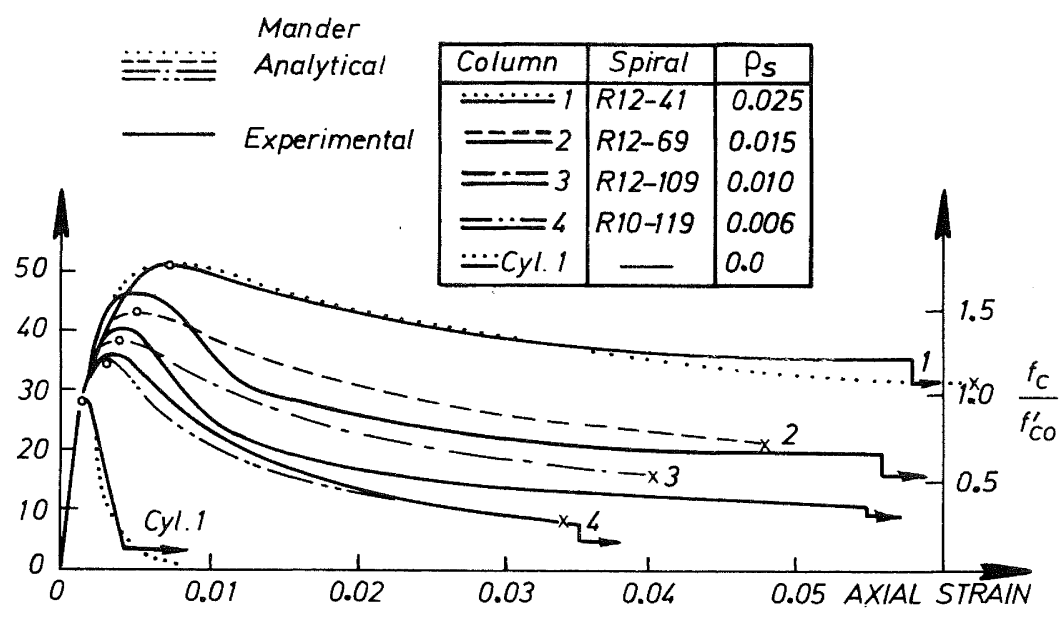

(b) Nieasured confined concrete stressstrain curve

Fig. 5 Reinforced Concrete Test Specimen and Longitudinal Stress-Strain Curves Measured for Confined Core With Various Quantities of Grade 275 Spiral Reinforcement (8) 
longitudinal steel, and dividing by the core area. Fig. 5 shows the effect of spiral steel content on the stress-strain relation. The increase in strength and ductility with increase in spiral steel content is significant.

Various investigators have proposed empirical stress-strain relationships for concrete confined by spirals or circular hoops. An early relation is that proposed by Park and Leslie (9), which was based on the limited test results from small specimens available at that time. Recently Mander, et al (8) have proposed a relationship based on the comprehensive program of tests conducted at the University of Canterbury after the installation of the 1000 tonne DARTEC universal testing machine in 1978. The relationship by Mander, et al, gives excellent agreement with experimental results (see Fig. 5) and includes the effect of rate of loading. The longitudinal concrete compressive strain corresponding to first fracture of the transverse reinforcement can be predicted with reasonable accuracy using an energy balance theory proposed by Mander, et al. The increase in strain energy stored by confined concrete, compared with unconfined concrete, is provided by the strain energy capacity of the confining steel as it yields in tension. By equating the ultimate strain energy capacity of the confining reinforcement per unit volume of concrete core to the difference in area between the confined and unconfined concrete stress-strain curves, plus the additional energy required to yield the longitudinal steel in compression, the concrete compressive strain corresponding to fracture of the transverse reinforcement may be found (8).

\subsection{Theoretical Determination of Moment-Curvature Relationships}

The available ductility of a pile subjected to lateral loading is mainly dependent on the shape of the momentcurvature relationship of the pile section, since most of the deformations of the pile arise from deformations associated with flexure. The theoretical moment-curvature relations for prestressed concrete pile sections can be calculated using the well established procedure for moment-curvature analysis which assumes that plane sections before bending remain plane after bending and which satisfies the requirements of strain compatibility and equilibrium of forces $(3,10)$. The stress-strain relations for concrete, nonprestressed steel and prestressing tendons required for the procedure are mathematically represented. It can be conservatively assumed that the cover concrete spalls at compressive strains greater than 0.004 . That is, the cover concrete and core concrete can be assumed to follow the same stress-strain curve up to a concrete strain of 0.004 but beyond that strain only the core concrete is effective.
The moment-curvature curve can be traced by calculating a number of points which define the curve. Fig. 6 a shows the section, strain and stresses for a particular combination of external force $P$ and moment $M$. To determine one point on the moment-curvature relation an extreme fibre concrete strain of $\varepsilon$ is specified and the corresponding neutral axis depth is found by iteration, in which strain compatibility is satisfied and the resultant of the internal forces is equal to the external axial load $P$. The moment $M$ and curvature $\phi$ corresponding to this extreme fibre concrete strain $\varepsilon_{c m}$ are then determined and plotted to give a point on the moment-curvature curve. The moment-curvature curve is traced out by repeating the calculation for a range of extreme fibre concrete compressive strains. The procedures are outlined in more detail elsewhere $(3,10)$.

\subsection{Code Equations for Confining Reinforcement}

Codes of the American Concrete Institute have since 1963 (see Ref. 4) recommended the following equation for the quantity of spiral reinforcement to be placed in reinforced concrete columns

$\rho_{\mathrm{S}}=0.45 \frac{\mathrm{f}_{\mathrm{C}}^{\prime}}{\mathrm{f}_{\mathrm{yh}}}\left(\frac{\mathrm{A}_{\mathrm{g}}}{\mathrm{A}_{\mathrm{C}}}-1\right)$

This equation is based on the concept of providing sufficient spiral reinforcement to ensure that the increase in the strength of the concrete core due to confinement compensates for the loss of strength of the cover concrete when it spalls.

United States codes, for example the SEAOC requirements (11), have used Eq. I with a lower limit of $0.12 \mathrm{f}_{\mathrm{C}} / \mathrm{f}_{\mathrm{yh}}$ to
specify the spiral reinforcement required in the potential plastic hinge zones of reinforced concrete spiral columns in seismic design. However, the philosophy of maintaining the concentric load strength of column sections after the spalling of cover concrete does not properly relate to the detailing requirements of adequate plastic rotation capacity of eccentrically loaded members. The confining steel so designed by the SEAOC code will obviously improve the plastic rotation capacity of the column but can only be regarded as a crude guide to the amount of confining steel actually required for ductile behaviour.

A more logical approach for the determination of the amount of transverse reinforcement necessary to achieve adequate curvature ductility would be based on ensuring a satisfactory momentcurvature relationship. Theoretical moment-curvature analyses of reinforced concrete columns have been conducted in New Zealand (for example Refs. 3 and 9) to determine the influence of quantity of confining steel on the available curvature ductility. The idealised stress-strain curves for confined concrete 
used in these analyses were based on a limited number of tests on small specimens but the curves used were generally considered to be conservative. The complete stress-strain curve for confined concrete was used in the analyses. That is, the full extent of the "falling branch" of the stress-strain curve after the maximum stress was reached was utilised. The available curvature ductility factor of the section was judged by assessing the curvature after maximum moment was reached when the section was still carrying a reasonable proportion of the maximum moment.

Fig. $6 \mathrm{~b}$ shows diagramatically the form of the moment-curvature curves obtained for a particular column section with different transverse steel contents and a constant compressive load level. Theoretical moment-curvature relations for a range of transverse steel contents and compressive load levels were computed. The analyses show that the quantity of transverse steel specified by the SEAOC code (11) was conservative for low load levels but was unconservative for high load levels. Hence a modification to account for compressive load levels was introduced into the equations for the New Zealand concrete design code. The modification results in an increase in transverse steel content with increase in compressive load level.

It can be reasoned from first principles, without a moment-curvature analysis, that a dependence between load level and transverse steel content should exist. A higher compressive load level means a larger neutral axis depth which in turn means that the flexural strength of the column is more dependent on the contribution of the concrete compressive stress block. Thus the higher the load the more important it becomes to maintain the strength and ductility of the concrete, thus leading to a greater quantity of transverse steel.

The New Zealand code rules for confining reinforcement for reinforced concrete columns should also apply in general to prestressed concrete piles, with some exceptions which will be discussed below.

\section{NEW ZEALAND CODE PROVISIONS FOR DETAILING OF CONCRETE COMPRESSION MEMBERS FOR DUCTILITY}

\subsection{Length of Potential Plastic Hinge Region for Confinement}

In the New Zealand code (4) the length of the potential plastic hinge region in the ends of columns to be confined is taken as the longer section dimension in the case of a rectangular section or the diameter in the case of a circular section, or where the moment exceeds 0.8 of the maximum moment at that end of the member. When the compressive load level exceeds $0.3 \mathrm{f}_{\mathrm{C}}^{\mathrm{A}} \mathrm{g} \phi$ this length
is increased by $50 \%$.
The above rule is for columns where the maximum moments occur at the ends. For piles the exact distribution of moments along the pile is not so well known and there is a region of high moment at some distance away from the pile cap (see Fig. 1). In addition, the driven length of pile is not known exactly when the pile reinforcement is designed. Hence for piles it would appear to be necessary to carry the confining steel along most of the length of the pile.

\subsection{Anchorage of Transverse Reinforcement for Confinement}

In the New Zealand code (4) it is required that transverse steel shall be anchored by at least a $135^{\circ}$ hook around a longitudinal bar plus an extension of at least eight transverse bar diameters at the free end of the bar into the core concrete of the members. Alternatively, the ends of the transverse bars shall be welded.

Note that the loss of concrete cover as a result of spalling during plastic hinge rotation, means that the transverse steel must be carefully detailed. It is inadequate to lap splice the spiral or circular hoop in the cover concrete. If the concrete cover is going to spall, the spiral or circular hoop will be able to unwind (as was observed in bridge piers during the 1971 San Fernando earthquake). Therefore full strength lap welds, or ends anchored by bending back into the core concrete as specified, is required.

\section{3 \\ Spacing of Transverse Reinforcement for Confinement}

In the New Zealand code (4) the centre to centre spacing of transverse confining reinforcement in the longitudinal direction of the column in potential plastic hinge regions is required not to exceed the smaller of one-fifth of the least lateral dimension of the cross section, six longitudinal bar diameters, or $200 \mathrm{~mm}$.

With regard to the above limits on longitudinal spacing of transverse reinforcement, the one-fifth of the least column lateral dimension requirement is to ensure that the transverse bars are close enough to effectively confine the compressed concrete, and this requirement should also be adequate in the case of prestressed concrete piles. The six longitudinal bar diameter requirement is to ensure that buckling of compressed longitudinal reinforcing bars does not occur. In prestressed concrete piles the prestressing strand may need to act as compression reinforcement at large deformations, and it may be that six strand diameters will not prevent buckling of the individual wires making up the strand. Hence a smaller spacing of transverse reinforcement may be necessary in prestressed concrete piles than in 


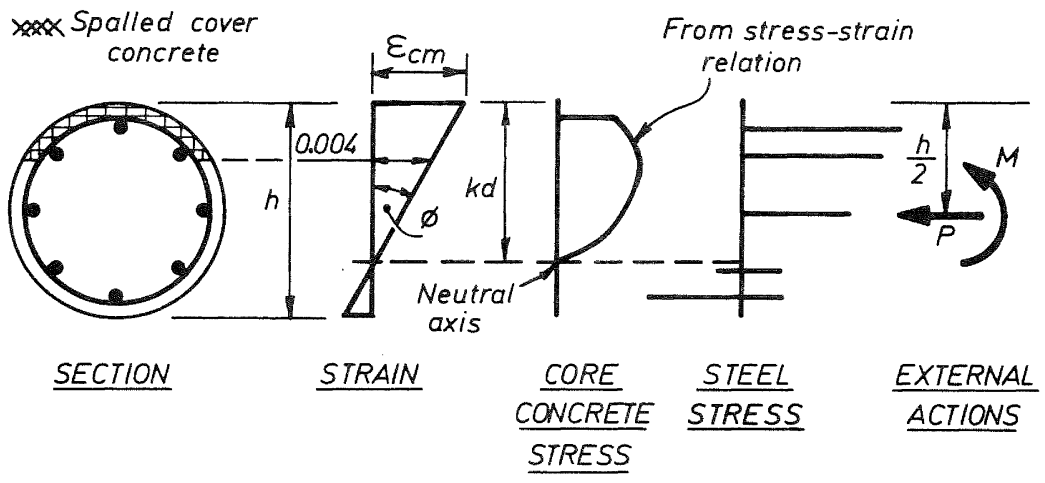

(a) Moment-curvature analysis
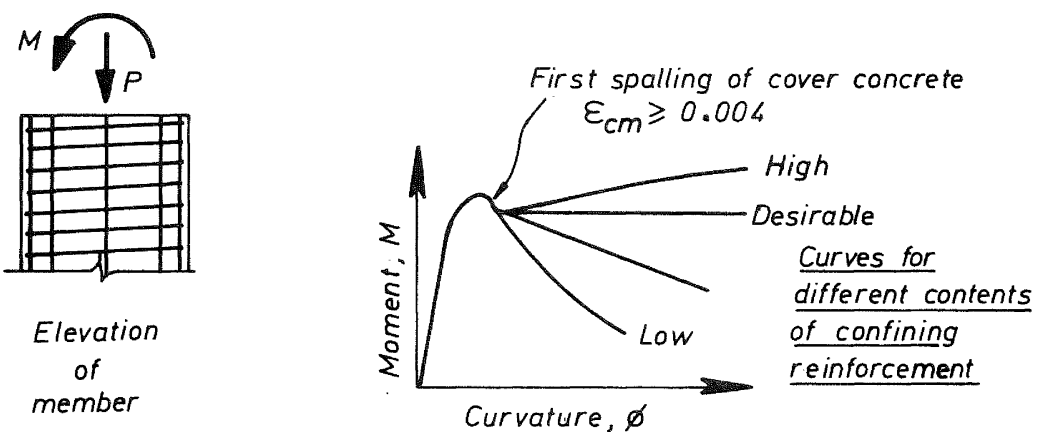

(b) Moment-curvature relations for constant axial load

Fig. 6 Ductility Analysis of Prestressed Concrete Pile Sections

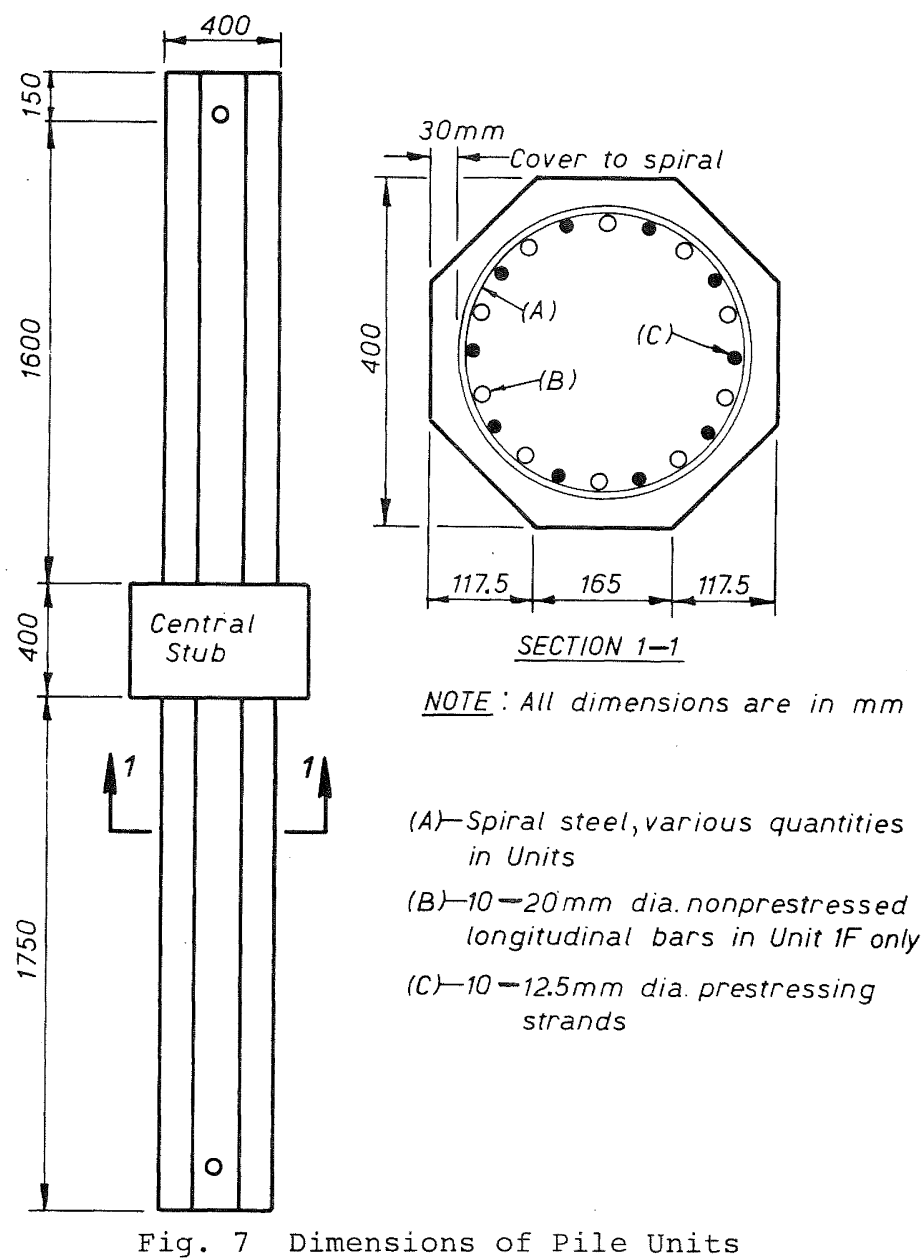


reinforced concrete compression members.

3.4 Quantity of Transverse Reinforcement Required for Confinement in Potential Plastic Hinge Regions of Columns

Generally the quantity of transverse reinforcement of circular shape for confinement is expressed in terms of $\rho$, which is the ratio of the volume of spiral or circular hoop reinforcement to the volume of the concrete core. Therefore

$\rho_{s}=\frac{A_{s p} \pi d_{s}}{s \pi\left(d_{s} / 2\right)^{2}}=\frac{4 A_{s p}}{d_{s} s}$

The approach adopted by the New Zealand code (4) is to specify quantities of transverse reinforcement which should ensure adequate ductility at the plastic hinge regions in the columns for the level of seismic design force used.

In potential plastic hinge regions of reinforced concrete columns when spirals or circular hoops are used, the New Zealand code requires that the volumetric ratio $\rho_{\mathrm{s}}$ shall not be less than

$\rho_{S}=0.45\left(\frac{A_{g}}{A_{C}}-1\right) \frac{f_{C}^{\prime}}{f_{Y h}} K$

or $\rho_{s}=0.12 \frac{f_{c}^{\prime}}{f_{y h}} k$

where $\mathrm{K}=0.5+1.25 \frac{\mathrm{P}_{\mathrm{e}}}{\phi \mathrm{f}_{\mathrm{C}}^{\prime} \mathrm{A} g}$

whichever is greater.

The compressive column load due to the design gravity and seismic loading, $\mathrm{P}_{e^{\prime}}$ is not permitted to exceed $0.7 \phi f_{C}^{\prime A}$ unless it can be shown that $P$ is less than $0.7 \phi \mathrm{P}$. This upper limit on the column load is placed because with very heavily loaded sections the available ductility is doubtful even with large amounts of confining steel.

In the case of prestressed concrete piles a case can be made for including the level of axial prestressing force with $\mathrm{P}$ in $\mathrm{Eq}$. 5, since the prestress increases the net compression force to be carried by the concrete. To affect this $K$ would be changed to

$K=0.5+\frac{1.25}{\phi f^{\prime}{ }_{C}}\left(\frac{P_{e}}{A_{g}}+f_{p}\right)$

where $f$ is the axial compressive stress in the Eoncrete due to prestress.

Note that prestressed concrete piles may not need the full quantity of spiral steel specified by Eqs. 3 to 6 . If a piled foundation has been protected by capacity design procedures, so that energy dissipation occurs in the structure above foundation level, it may be that less confinement steel in the piles than specified for "full ductility" may be adequate to cope with the limited ductility demand imposed during a severe earthquake. Therefore the performance of piles with smaller quantities of spiral steel than the full code specified amount is of interest.

4. TESTS ON FULI SCALE PRESTRESSED CONCRETE PILES SUBJECTED TO SIMULATED SEISMIC LOADING

\subsection{General Details}

Eleven pretensioned prestressed concrete piles were designed, constructed and tested. The overall dimensions of the pile units are shown in Fig. 7. Each pile had a $400 \mathrm{~mm}$ wide octagonal cross section and a total height of $3.9 \mathrm{~m}$, with a reinforced concrete stub at mid-height. The region of the pile above and below the central stub could be regarded as being that part of a prototype pile adjacent to the pile cap. The concrete cover to the spiral steel was $30 \mathrm{~mm}$. Each pile was prestressed by a total of ten $12.5 \mathrm{~mm}$ diameter prestressing strands. The strand used was stress relieved and uncoated. The strand used in the piles of Falconer and Park $(5,6)$ had surface indentations in four of the outer wires, but in the piles of Pam and Park (7) the strand had no surface indentations.

The strand was stressed in a commercial pretensioning bed, either $27.7 \mathrm{~m}$ or $22 \mathrm{~m}$ long between end posts. The tendons were stressed in increments up to the desired level of about $0.7 \mathrm{f}$ and steel tension was checked by bothpuack pressure and steel elongation measurements. After the concrete had gained sufficient strength, the tendon force was transferred to the concrete by releasing the tendons gradually from the end posts. Fig. 8 shows aspects of the construction of the pile units.

It should be noted that the development length of the strand from the end of the pile unit to the section of maximum moment adjacent to the central column stub was $140 d_{\text {, where }} d_{b}=12.5 \mathrm{~mm}$ was the strand diameter. The required development length for seven wire prestressing strand formed from plain wires is approximately $150 \mathrm{~d}$ according to the New Zealand code (4), but it was felt that the reduced development length would be satisfactory. This confidence was supported by the test performance of the piles which did not indicate any bond failure.

\subsection{Details of Pile Units}

Table 1 summarises the material strengths and steel details for the two projects. Figs. 9 and 10 show typical measured stress-strain curves for the steel reinforcement and prestressing strand used in the piles.

of the piles tested only Unit IF 
Table 1 : Details of Prestressed Pile Units

\begin{tabular}{|c|c|c|c|c|c|c|c|c|c|c|c|c|}
\hline \multirow{3}{*}{$\begin{array}{l}\text { Pile } \\
\text { Unit }\end{array}$} & \multirow{3}{*}{$\frac{P_{e}}{f_{c}^{\prime A} g}$} & \multirow{2}{*}{\multicolumn{2}{|c|}{$\begin{array}{l}\text { Concrete }(a) \\
\text { Strength } \\
\mathrm{f}_{C}^{\prime} \mathrm{f}_{r}\end{array}$}} & \multirow{2}{*}{\multicolumn{2}{|c|}{$\begin{array}{l}\text { Prestressing } \\
\text { Steel } \\
12.5 \mathrm{~mm} \text { Strand }\end{array}$}} & \multirow{2}{*}{$\begin{array}{l}\text { Prestress } \\
\text { in } \\
\text { Concrete }(a)\end{array}$} & \multicolumn{6}{|c|}{ Spiral Reinforcement } \\
\hline & & & & & & & \multirow{2}{*}{ Dia. } & \multirow{2}{*}{$\mathrm{s}$} & \multirow{2}{*}{$f_{y h}$} & \multirow{2}{*}{$\rho_{\mathrm{S}}$} & \multirow{2}{*}{$\frac{\rho_{S}(b)}{\rho_{S} \operatorname{code}}$} & \multirow{2}{*}{$\frac{\rho_{S}(c)}{\rho_{S}^{\prime c o d e}}$} \\
\hline & & & (MPa) & $\frac{A_{p t}}{A_{g}}$ & $\begin{array}{l}f_{\mathrm{pu}} \\
(\mathrm{MPa})\end{array}$ & $(\mathrm{MPa})$ & & & & & & \\
\hline & & & & \multicolumn{3}{|c|}{$\begin{array}{l}\text { Units Tested by Falconer } \\
\text { and Park }(5,6)\end{array}$} & \multirow[b]{2}{*}{10} & \multirow[b]{2}{*}{35} & & \multirow[b]{2}{*}{0.0264} & \multirow[b]{2}{*}{1.12} & \multirow[b]{2}{*}{0.84} \\
\hline $1 F^{(d)}$ & 0.3 & 37.0 & 5.4 & 0.0073 & 1824 & 8.44 & & & 284 & & & \\
\hline $2 \mathrm{~F}$ & 0.3 & 38.7 & 5.0 & 0.0073 & 1824 & 8.54 & 10 & 35 & 284 & 0.0264 & 1.08 & 0.82 \\
\hline $3 \mathrm{~F}$ & 0.1 & 42.7 & 5.5 & 0.0073 & 1824 & 8.54 & 10 & 45 & 284 & 0.0205 & 1.06 & 0.76 \\
\hline $4 \mathrm{~F}$ & 0.3 & 33.6 & 4.3 & 0.0073 & 1824 & 8.54 & 10 & 130 & 284 & 0.0071 & 0.33 & 0.24 \\
\hline \multirow[t]{2}{*}{$5 \mathrm{~F}$} & 0.6 & 29.2 & 3.7 & 0.0073 & 1824 & 8.54 & 12 & 35 & 318 & 0.0380 & 1.62 & 1.26 \\
\hline & & & & \multicolumn{3}{|c|}{$\begin{array}{l}\text { Units Tested by Pam } \\
\text { and Park (7) }\end{array}$} & \multirow{7}{*}{$\begin{array}{l}10 \\
12 \\
7.5 \\
7.5 \\
7.5 \\
7.5\end{array}$} & \multirow{7}{*}{$\begin{array}{l}75 \\
75 \\
75 \\
60 \\
50 \\
75\end{array}$} & \multirow{7}{*}{$\begin{array}{lll}3 & 2 & 5 \\
3 & 1 & 8 \\
5 & 1 & 1 \\
5 & 1 & 1 \\
5 & 1 & 1 \\
5 & 11\end{array}$} & \multirow{7}{*}{$\begin{array}{l}0.0123 \\
0.0177 \\
0.00693 \\
0.00866 \\
0.0104 \\
0.00693\end{array}$} & \multirow{7}{*}{$\begin{array}{l}0.44 \\
0.56 \\
0.46 \\
0.48 \\
0.60 \\
0.34\end{array}$} & \multirow{7}{*}{$\begin{array}{l}0.37 \\
0.47 \\
0.36 \\
0.40 \\
0.50 \\
0.29\end{array}$} \\
\hline $1 \mathrm{P}$ & 0.3 & 50.3 & 5.48 & 0.0073 & 1845 & 7.24 & & & & & & \\
\hline $2 \mathrm{P}$ & 0.3 & 55.2 & 5.48 & 0.0073 & 1845 & 7.40 & & & & & & \\
\hline $3 P$ & 0.3 & 42.2 & 5.14 & 0.0073 & 1845 & 7.74 & & & & & & \\
\hline $4 \mathrm{P}$ & 0.3 & 51.2 & 4.10 & 0.0073 & 1845 & 7.15 & & & & & & \\
\hline $5 \mathrm{P}$ & 0.3 & 48.7 & 4.10 & 0.0073 & 1845 & 7.20 & & & & & & \\
\hline $6 \mathrm{P}$ & 0.5 & 44.5 & 5.14 & 0.0073 & 1845 & 7.66 & & & & & & \\
\hline
\end{tabular}

(a) At time of testing pile

(b) $\rho$ code based on measured material strengths at time of testing and $\phi=1$.

(c) Prestress included as axial load in calculation of $\rho$ 'code.

(d) Unit IF included 2.37\% longitudinal reinforcement provided by $10-D 20$ bars, $\mathrm{f}_{\mathrm{Y}}=292 \mathrm{MPa}$.

Table 2 : Test and Analytical Results for Prestressed Pile Units

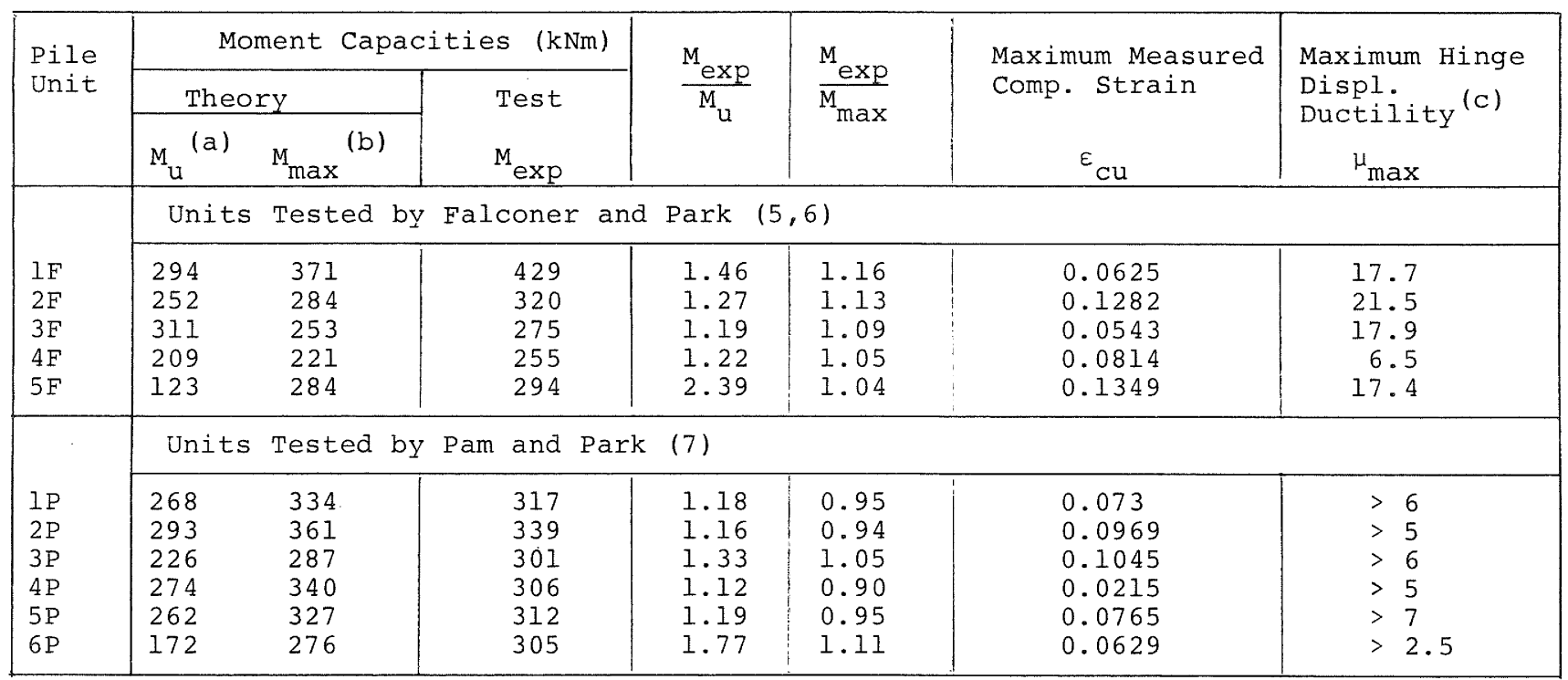

(a) $M_{u}$ based on ACI stress block, $\varepsilon_{C m}=0.003$, measured material strengths and $\phi=1$.

(b) $\mathrm{M}^{\mathrm{u}}$ based on moment-curvature analysis using Park-Leslie stress-strain curve.

(c) Maximum displacement ductility from top or bottom plastic hinge at end of test, or where moment has not dropped below $0.8 \mathrm{M}$ exp or where the spiral fracture occurred; $\mu_{\max }=(\Delta+\theta \mathrm{h}) / \Delta_{\mathrm{y}^{\prime}}$ as in Fig. 17 . 


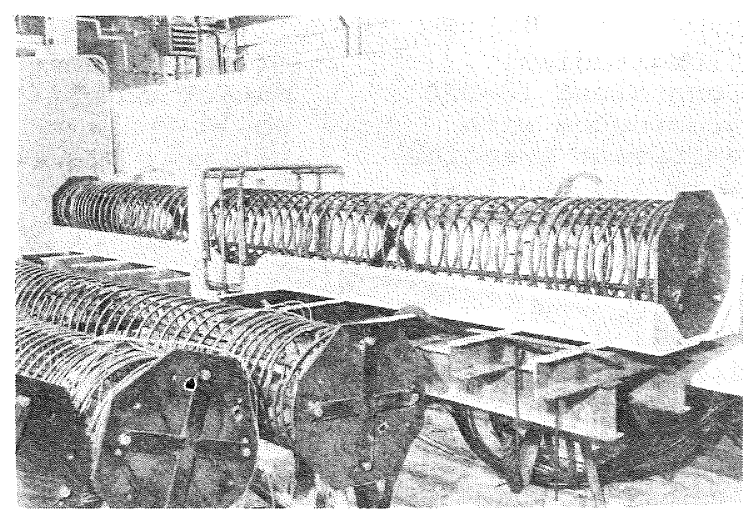

(a) Spiral cages ready for placing in stressing bed

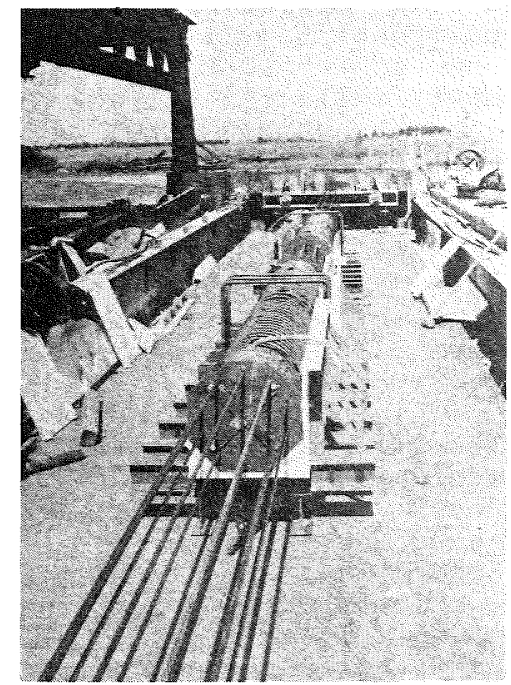

(b) Tendons ready for tensioning

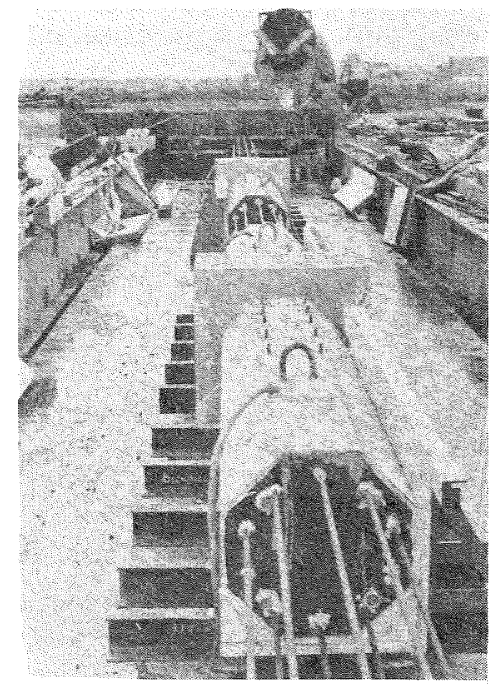

(c) Mould sides stripped off after casting

Fig. 8 Construction Stages of Pile Units

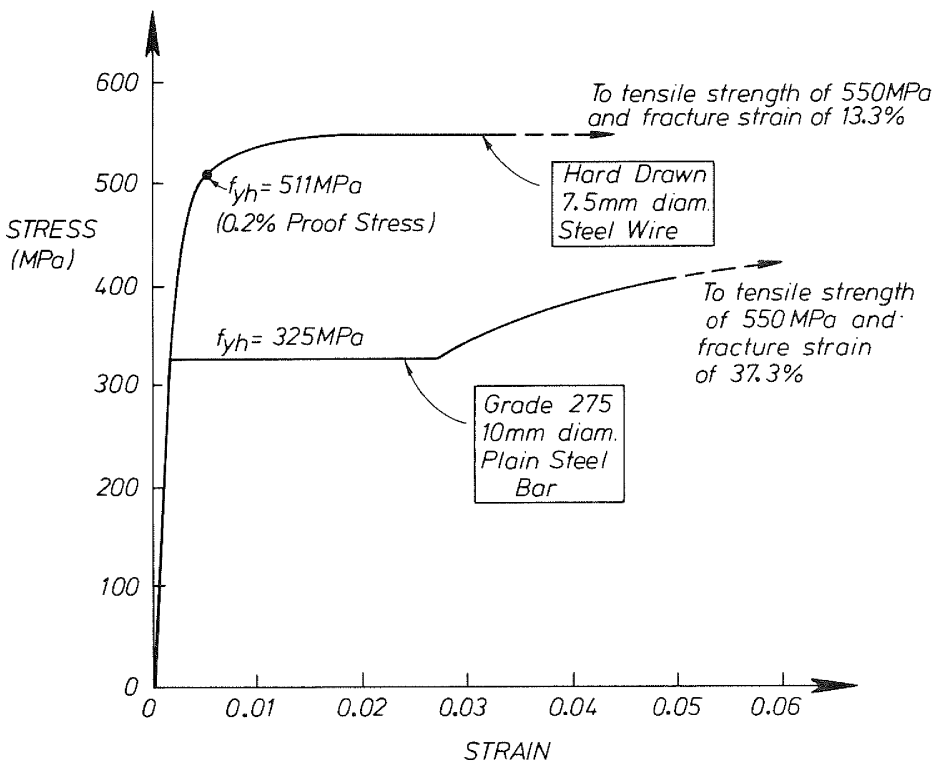

Fig. 9 Typical Measured Stress-Strain Curves for Grade 275 and Hard Drawn Steel Reinforcement 
contained nonprestressed longitudinal reinforcement. This unit contained 10-D20 Grade 275 steel bars in accordance with Ministry of Works and Development practice current at the time of designing the test units. Longitudinal reinforcement for the other units was provided solely by the prestressing strand.

Most of the pile units were tested under an axial load level of $\mathrm{P}=0.3 \mathrm{f}_{\mathrm{C}} \mathrm{A} \mathrm{g}^{\prime}$
although three units were tested at different levels, between 0.1 f'A $^{\prime} \mathrm{and}$ $0.6 \mathrm{f}$ 'A to investigate the influence of axial load level. The value of $0.3 \mathrm{f}_{\mathrm{C}}^{\prime A}$ was felt to represent a realistic upper limit to the level of compressive external load carried by a prestressed pile under seismic loading.

Units $1 F$ to $5 F$ contained Grade 275 spiral reinforcement. The ratio of confinement provided to code level calculated using Eqs. 3 to 5 for the level of axial load is listed in the second column from the right in Table 1 . The quantity of confining reinforcement provided for Units $1 \mathrm{~F}, 2 \mathrm{~F}$ and $3 \mathrm{~F}$ was close to the code required value. Unit $5 \mathrm{~F}$ had $62 \%$ excess confinement. Unit $4 \mathrm{~F}$ was deliberately provided with a much lower level of confinement than required by the New Zealand code provisions. At $s=130 \mathrm{~mm}$, the spiral pitch for this unit also exceeded the limitations of $6 \mathrm{~d}_{\mathrm{b}}=75 \mathrm{~mm}$, and $\mathrm{D} / 5=80 \mathrm{~mm}$, where $\mathrm{d}_{\mathrm{b}}=$ longitudinal bar diameter (taken as prestressed strand diameter) and $\mathrm{D}=$ pile diameter.

Units IP to $5 \mathrm{P}$ contained 44 to $60 \%$ of the quantity of confining reinforcement required by the code, while unit 6P, which was subjected to a higher axial load level, contained only $34 \%$ of the code confinement. The confinement for Units $1 \mathrm{P}$ and $2 \mathrm{P}$ was provided by Grade 275 reinforcement, but the other four units were confined by $7.5 \mathrm{~mm}$ diameter hard drawn steel wire.

The hard drawn steel wire used had a guaranteed yield strength $10.2 \%$ proof stress) of $485 \mathrm{MPa}$. This wire had the advantage of being available in coils of considerable length, obviating the need for lap welding the spiral every six or so pitches, as is necessary for Grade 275 steel spirals. The potential savings in labour and construction time associated by eliminating welding are substantial.

Since the quantity of confining reinforcement required by the New Zealand code Eqs. 3 to 5 are inversely proportioned to $f$, the spiral yield strength, the codetallows considerable reduction in volume of confining steel when high strength steel is used. However, the smaller fracture strain of hard drawn steel reinforcement may cause premature spiral fracture. It is significant that the strain at fracture of the hard drawn wire of Units $3 \mathrm{P}$ to $6 \mathrm{P}$, at $13.3 \%$, was only about $37 \%$ of the strain at fracture for the Grade 275 steel used for the spirals of Units $1 P$ and $2 P$. The fracture strain was measured over a gauge length of $5 \mathrm{~d}_{\mathrm{b}}$. The energy balance approach of Mander et al (8), referred to previously, would indicate that a similar reduction in ultimate curvature would result from the use of hard drawn wire instead of Grade 275 steel for spiral reinforcement.

As discussed previously, in the design of prestressed concrete piles it would be logical to include the prestressing force with the external axial load $\mathrm{P}$ when calculating the required volumetric ratio of confining reinforcement. That is, $\mathrm{K}$ in Eqs. 3 and 4 could be given by Eq. 6 rather than Eq. 5. The right column in Table 1 lists the ratio of confinement provided to code confinement based on the above modification. It will be seen that Unit $4 \mathrm{~F}$ now contains only $24 \%$ of code confinement, while the Units $1 \mathrm{P}$ to $6 \mathrm{P}$ contain amounts varying from 29 to $50 \%$ of the code level of confinement.

\subsection{Test Procedure and Results}

Fig. 11 shows the method of loading the pile units. The axial compressive load on the pile was maintained constant at the required level by a DARTEC universal testing machine and the reversed cyclic lateral load was applied at a slow rate in a displacement controlled pattern by a MTS actuator. The curvature at first yield was defined as the curvature at $75 \%$ of the theoretical flexural strength, found from the theoretical moment-curvature relation, multiplied by 1.33 . This definition for first yield curvature is illustrated in Fig. 12. It is fairly arbitrary but it serves as a convenient reference first yield curvature when the moment-curvature curve is not bilinear. The displacement at first yield $\Delta$ was calculated from an assumed pile curvature distribution which varied linearly from zero at the pile ends to this first yield curvature in the pile at the stub faces. A minimum of two displacement cycles were applied at various displacement ductility factors, generally $\mu= \pm 2, \pm 4, \pm 6$, etc. The piles were loaded dynamically at the end of the static loading tests.

The lateral load-deflection hysteresis loops for a selection of the pile units are shown in Figs. 13 and 14 Fig. $13 \mathrm{a}$ and $\mathrm{b}$ compare the behaviour of fully confined piles, with and without additional longitudinal Grade 275 steel reinforcement, respectively. Unit $1 F$, with additional longitudinal nonprestressed reinforcement had a higher ultimate lateral load, and rather "fatter" hysteresis loops, than Unit $2 \mathrm{~F}$ but in all other aspects the behaviour of the two units was similar. Both units were able to sustain average displacement ductility factors of up to $\mu= \pm 10$ while still substantially exceeding the theoretical lateral load capacity. Stability of the loops at displacement ductilities up to $\mu= \pm 8$ is excellent in both cases. It should be noted that the theoretical lateral load capacity decreases markedly with increasing lateral displacement due to the P- $\Delta$ effect. In Fig. 13 the 


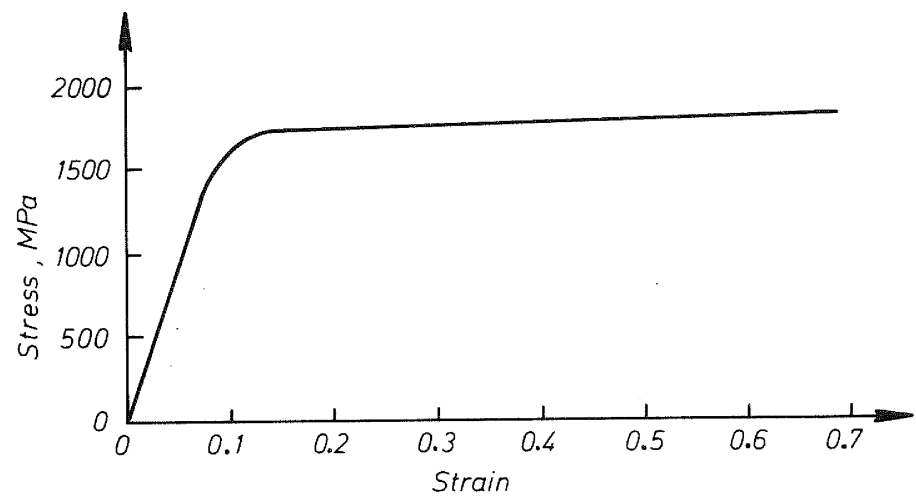

Fig. 10 Typical Measured Stress-Strain Curve for $12.5 \mathrm{~mm}$ Diameter Seven Wire Prestressing Strand

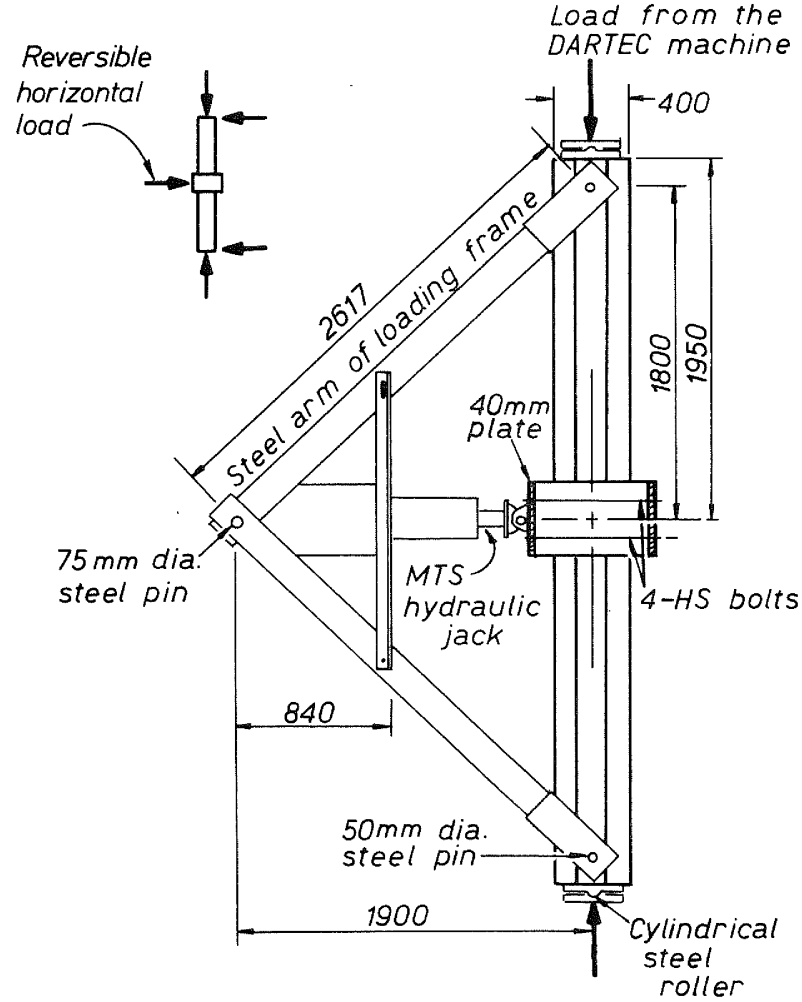

Fig. 11 Method of Loading the Pile Units

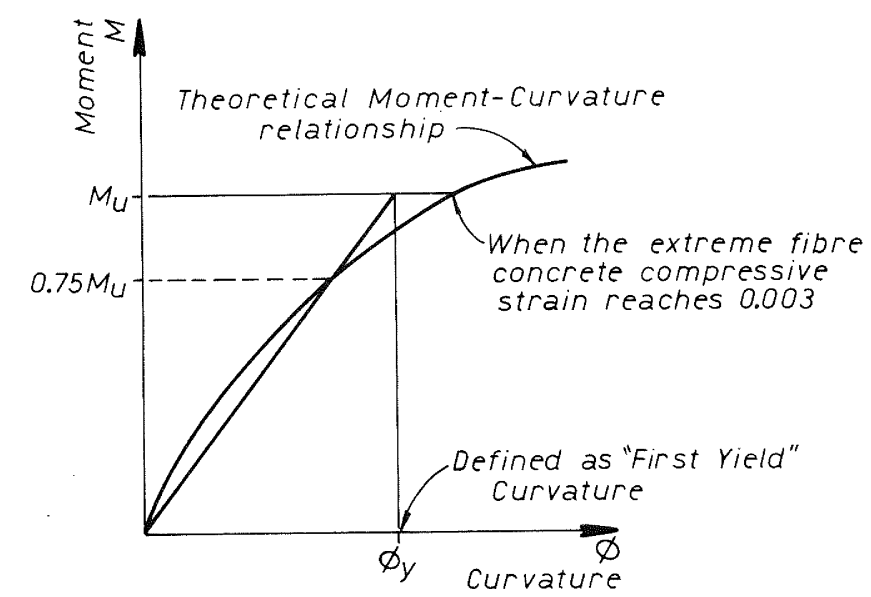

Fig. 12 Definition of First Yield Curvature 


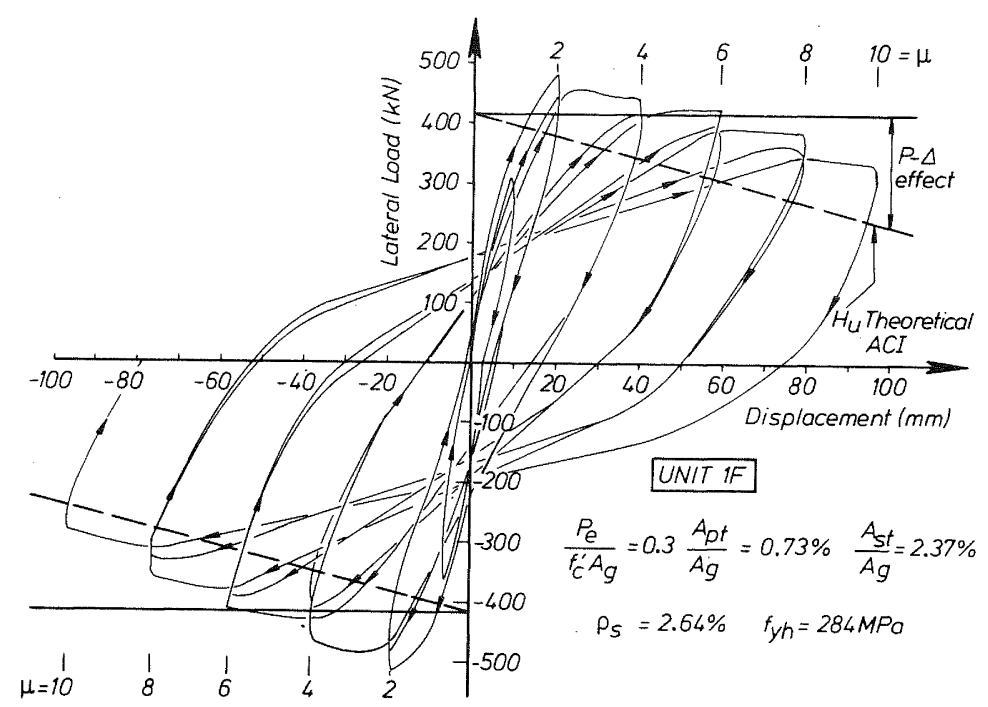

(a) Fully confined pile with nonprestressed longitudinal reinforcement

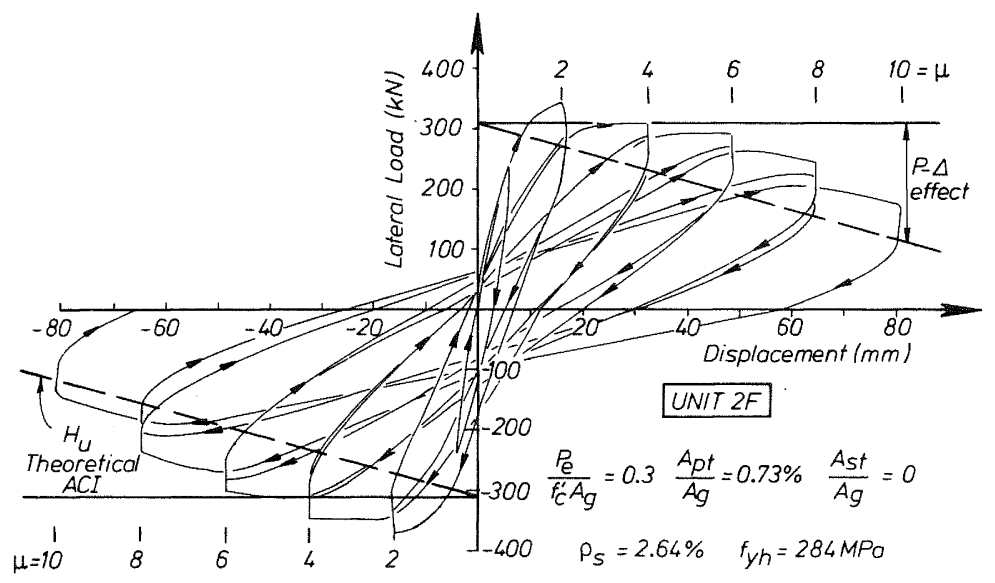

(b) Fully confined pile without nonprestressed longitudinal reinforcement

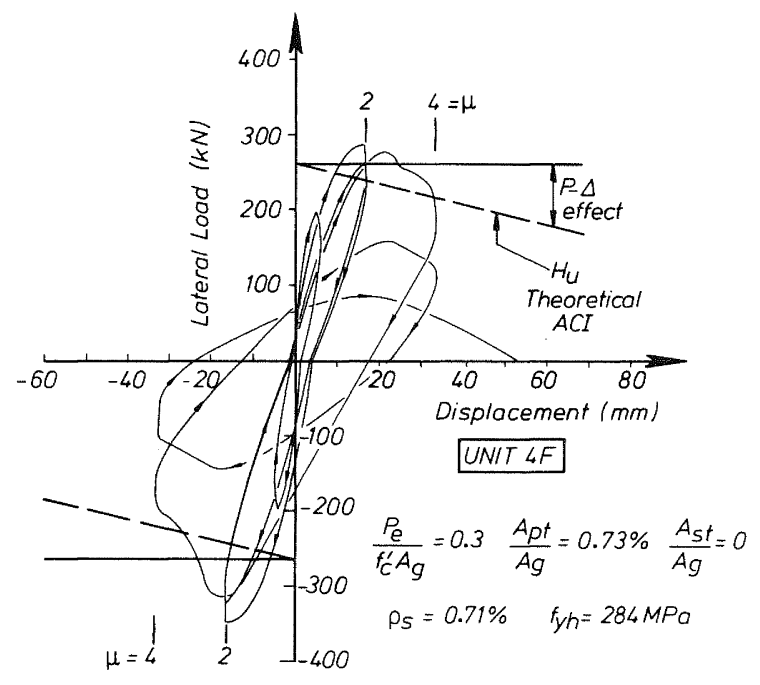

(c) Lightly confined pile

Fig. İ Lateral Load-Displacement Hysteresis Loops for Piles Tested by Falconer and Park $(5,6)$ 
theoretical lateral load capacity, $H$, is based on an ultimate compression strain of 0.003 , measured material properties, and the AC'I stress block for concrete in compression (4).

Unit $4 \mathrm{~F}$ contained only $33 \%$ of code required confining steel, based on the applied load level, and only $24 \%$ of the code confinement if the prestress is included in the total load carried by the concrete. Fig. 13c shows that this unit behaved well for displacement ductility factors of $\mu= \pm 2$, but degraded rapidly during cycles to $\mu= \pm 4$. This was primarily due to the large spiral pitch of $130 \mathrm{~mm}$, which resulted in inadequate confinement of the concrete core, and buckling of the longitudinal prestressing steel on the compression side of the column.

Figs. $15 \mathrm{a}$ and $\mathrm{b}$ show views of Unit $2 \mathrm{~F}$ at end of testing and of Unit $4 \mathrm{~F}$ at $\mu=4$, respectively. It will be observed that the core of Unit $2 \mathrm{~F}$ is well confined, and that concrete spalling has occurred only on one side of the plastic hinge. Under reversed loading, which would put the still competent side of the pile in compression, plastic hinging occurred solely in the top hinge (out of view in Fig. 15a). This behaviour, with plasticity concentrating in either the top or bottom potential plastic hinge positions, rather than being evenly spread between the two, was characteristic of the pile units, and resulted largely from the substantial loss of compression area when spalling of the cover concrete occurred. In Fig. 15b the wide spacing of the spiral steel, buckling of the prestressing strand, and vertical cracking of the lightly confined core of Unit $4 \mathrm{~F}$ are clearly apparent.

The partially confined pile Units IP to $6 \mathrm{P}$ typically exhibited satisfactory hysteresis loops at displacement ductility factors of $\mu= \pm 2$, but generally suffered excessive strength degradation during the second cycle to $\mu= \pm 4$, as a result of buckling of the prestressing strand, followed by a reduction of the effective core area and core crushing. Figs. $14 \mathrm{a}$ and $\mathrm{b}$ show typical hysteresis loops for piles confined by Grade 275 steel spirals and by hard drawn steel spirals, respectively. The hysteresis loops of Unit 6P shown in Fig. 14c suffered an earlier degradation of performance than the other units. This can be attributed to the higher axial load, and the lower proportion of code confinement provided for this pile.

It should be noted that the theoretical lateral load capacities, $\mathrm{H}_{\mathrm{u}}$ and the displacement ductility factors $\mu$ in Fig. 14 have been based on calculating the ultimate moment using an extreme fibre concrete compression strain of 0.003 and measured material properties, as with the units of Fig. 13, but have incorporated the confined stress-strain curve for concrete of Park and Leslie rather than the ACI stress block. As a consequence, the theoretical lateral loads for Units $1 \mathrm{P}$ and $3 \mathrm{P}$ in Figs. $14 \mathrm{a}$ and $\mathrm{b}$ are $16 \%$ higher than the ACI values, and for Unit $6 \mathrm{P}$ in Fig. $14 \mathrm{C}$ is $39 \%$ higher than the ACI prediction. The marked values of $\mu$ in the figure are high in proportion to these discrepancies.

Although the strength degradation of all the pile units was initially by loss of confinement occurring after buckling of the prestressing strand, further degradation occurred subsequently in the case of Units $3 P$ to $6 \mathrm{P}$ by spiral fracture of the hard drawn wire used as confining reinforcement. The average displacement ductility factor at spiral fracture was $\mu=6,4,6$ and 4 for Units $3 \mathrm{P}, 4 \mathrm{P}, 5 \mathrm{P}$ and $6 \mathrm{P}$, respectively.

Figs. 15d, e and $f$ show close-ups of the critical plastic hinges of Units $1 \mathrm{P}, 3 \mathrm{P}$ and $6 \mathrm{P}$ at the end of testing. Note that in Unit 1P, confined by Grade 275 steel, the spirals have not fractured, but the individual wires of the prestressing strand have buckled extensively. Spiral fracture, strand buckling and general concrete core degradation are apparent at the end of the tests of Units $3 \mathrm{P}$ and $6 \mathrm{P}$ confined by hard drawn wire, as shown in Fig. $15 e$ and $f$.

It should be noted that the ductility at the critical plastic hinge was always higher than that implied by the average displacement ductility factor $\mu$. This was because normally a concentration of plasticity for loading in a particular direction occurred at either the top or bottom plastic hinge. A typical example of the concentration of plasticity is shown in the curvature distributions at different ductility levels for Unit $3 \mathrm{P}$ shown in Fig. 16. It is apparent from this figure that virtually all the plastic rotation has occurred in the upper plastic hinge, under both directions of loading. The implication of this uneven distribution of plasticity above and below the central stub, resulting in rotation of the central stub, $\theta$, is illustrated in Fig. 17. Table 2 lists in the right column estimates of the maximum displacement ductility factor $\mu_{\max }$ on the critical plastic hinge rotation either above or below the central stub. The $\mu$ values are for either at the end of the max test, or where the moment reduced to below $80 \%$ of the maximum experimental moment. It will be seen that all pile units except Unit $6 \mathrm{P}$ achieved $\mu$ values greater than 5. However stablemaxsteresis behaviour could only be depended on for the partially confined Units $I P$ to $5 \mathrm{P}$ for $\mu_{\max }$ of about \pm 4 and Unit $6 \mathrm{P}$ for $\mu_{\max }$ of abouxt \pm 2.5

Table 2 also includes the maximum recorded concrete compression strains at the edge of the confined core. 


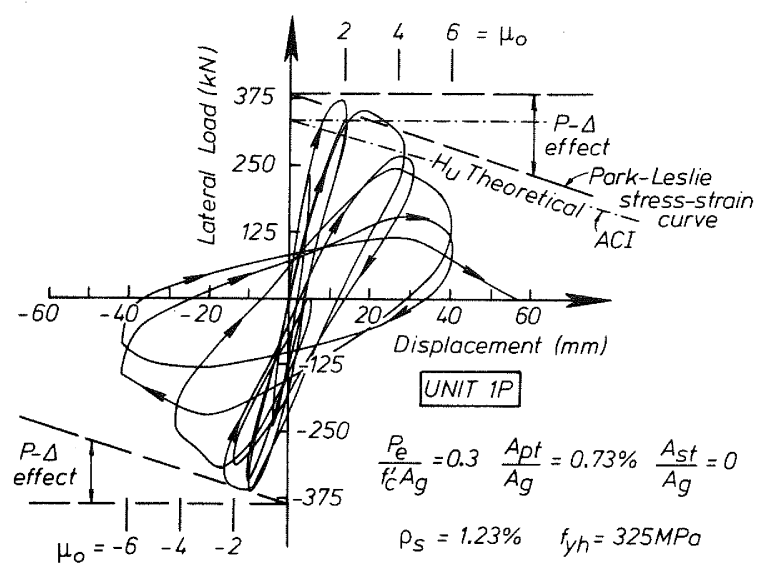

(a) Partially confined pile with Grade 275 steel spiral

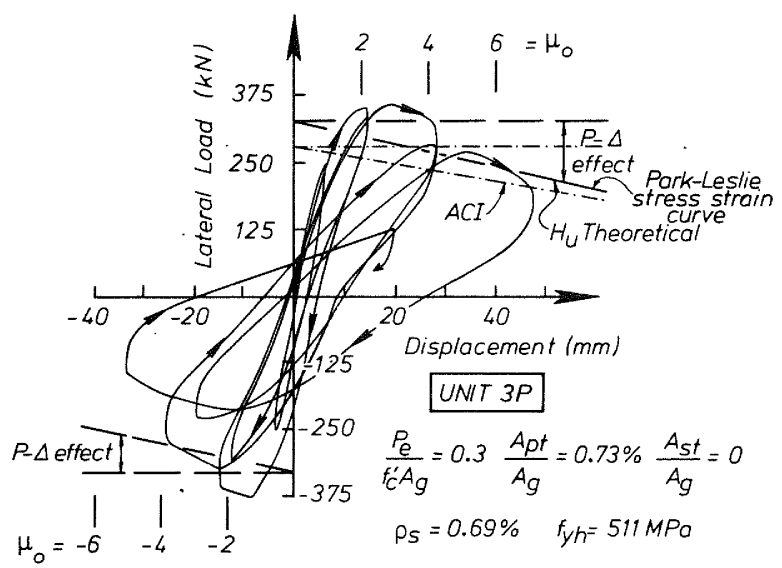

(b) Partially confined pile with hard drawn steel spiral

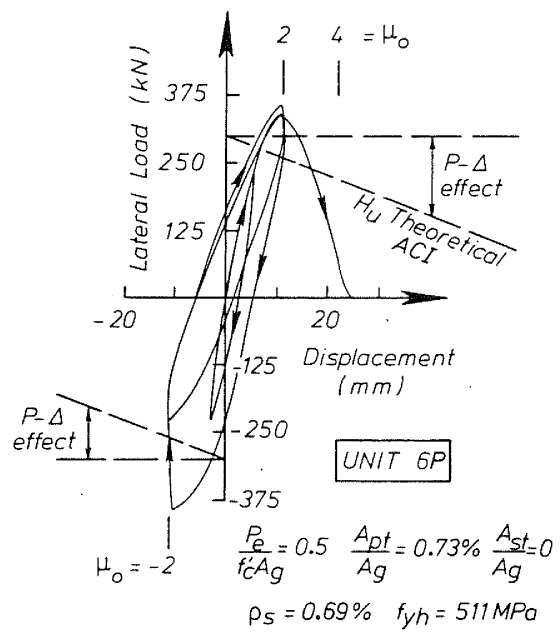

(c) Partially confined pile with hard drawn steel spiral and high axial load level

Fig. 14 Lateral Load-Displacement Hysteresis Loops for Prestressed Piles Tested by Pam and Park (7) 


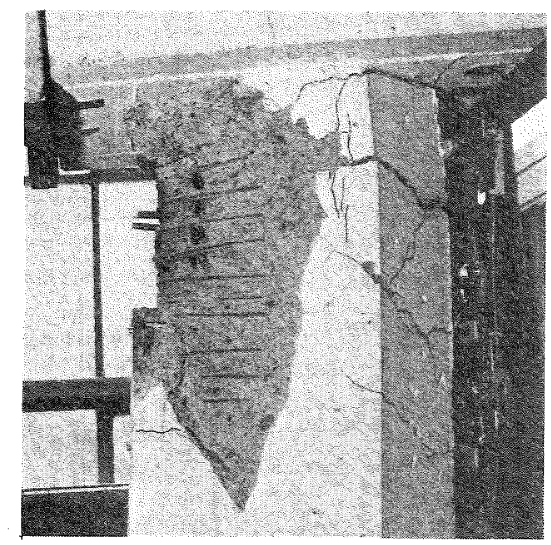

(a) Unit $2 \mathrm{~F}$ at $\mu=10$

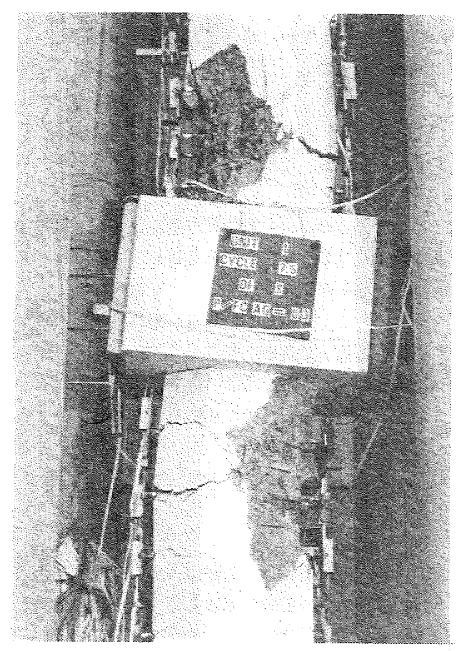

(c) Unit IP at end of test

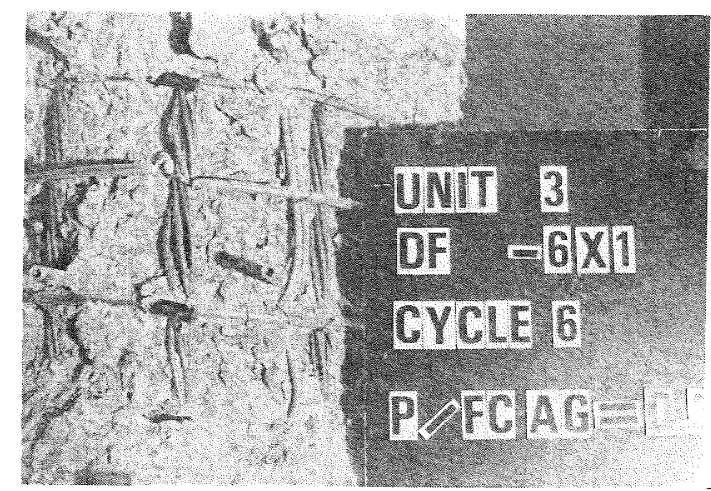

(e) Unit $3 P$ at $\mu_{0}=-6$

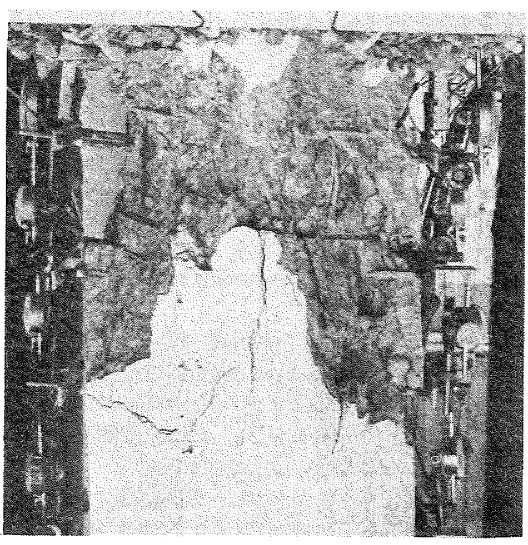

(b) Unit $4 \mathrm{~F}$ at $\mu=4$

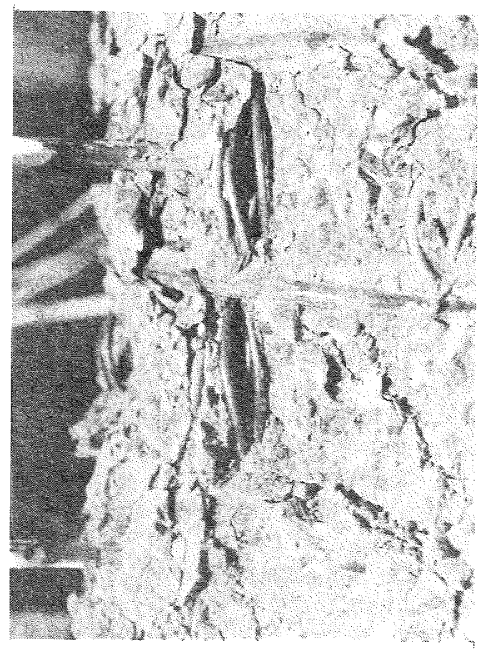

(d) Unit IP at end of test

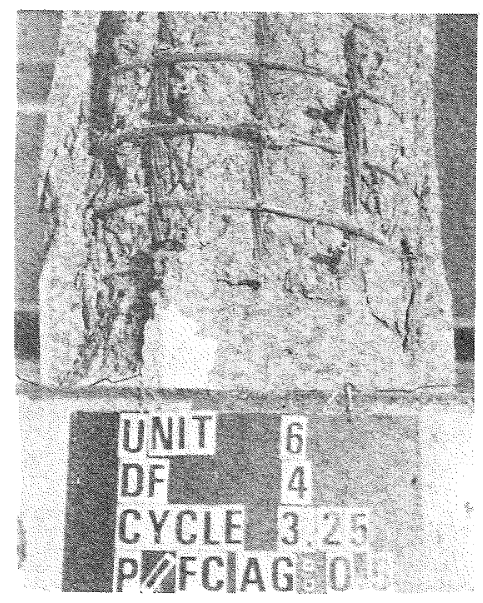

(f) Unit $6 \mathrm{P}$ at end of test

Fig. 15 Conditions of Piles at End of Testing 


\subsection{Theoretical Results}

Table 2 summarises the theoretical flexural strength results for both series of pile tests and compares the theoretical and experimental flexural strengths. The theoretical flexural strengths are calculated by the ACI approach and by a refined moment-curvature analysis approach.

The ACI approach used the conventional concrete compressive stress block (4), an extreme fibre concrete compressive strain of 0.003 , the measured material strengths and a strength reduction factor of $\phi=1.0$. Table 2 indicates that the ACI predictions of flexural strength are very conservative, particularly at high axial loads where flexural strength enhancement of up to $139 \%$ was obtained. This is because the ACI concrete compressive stress block is based on the stress-strain curve for unconfined concrete, whereas confinement improves the stress-strain behaviour of the concrete. The effect of this improvement on the column flexural strength is particularly noticeable when the neutral axis depth is large since then the concrete makes a large contribution to the flexural strength.

The refined moment-curvature analysis approach used the Park and Leslie (9) stress-strain curve for concrete confined by spirals. The assumed stressstrain curves for the confined concrete of the pile Units $1 \mathrm{~F}$ to $5 \mathrm{~F}$ are shown in Fig. 18a. The stress-strain curve for confined concrete is divided into four regions ALBCD as shown in the figure defined by the following equations (9):

Region AL: $0 \leqq \varepsilon_{C} \leqq 0.002$

$f_{C}=f_{C}^{\prime}\left[\frac{2 \varepsilon_{C}}{0.002}-\left(\frac{\varepsilon_{C}}{0.002}\right)^{2}\right]$

Region LB: $0.002 \leqq \varepsilon_{\mathrm{C}} \leqq \varepsilon_{\mathrm{CC}}$

$$
\begin{aligned}
f_{C}=f_{C}^{\prime}+ & \left(f_{C C}^{\prime}-f_{C}^{\prime}\right)\left[\frac{2\left(\varepsilon_{C}-0.002\right)}{\varepsilon_{C C}-0.002}\right. \\
& \left.-\left(\frac{\varepsilon_{C}-0.002}{\varepsilon_{C C}-0.002}\right)^{2}\right]
\end{aligned}
$$

where $f_{C C}^{\prime}=f_{C}^{\prime}\left[1+2.3\left(\rho_{S}-\bar{\rho}_{S}\right) f_{y h}\right]$

and $\varepsilon_{C C}=0.002\left[1+23\left(\rho_{s}-\bar{\rho}_{S}\right) \frac{f_{y h}}{f_{C}^{\prime}}\right]$

Region $B C: \varepsilon_{C C} \leqq \varepsilon_{C} \leqq \varepsilon_{20 C}$

$f_{C}=f_{C C}^{\prime}\left[1-z\left(\varepsilon_{C}-\varepsilon_{C C}\right)\right]$

where $z=\frac{107}{f_{C C}^{\prime}}\left(\frac{f_{C}^{\prime}}{\rho_{S_{y h}}}\right)^{1.13}$
Region $C D: \varepsilon_{20 C} \leqq \varepsilon_{C}$

$\mathrm{f}_{\mathrm{C}}=0.2 \mathrm{f}_{\mathrm{C}}^{\prime}$

For the assumed stress-strain curve for the prestressing tendon shown in Fig. 18b, in tension the curve measured in tests is followed closely but in compression the tendon is assumed to buckle at a compressive strain of 0.005 and then to maintain constant stress at higher strains. It is to be noted that at high curvatures the tendons in the compression zone of the concrete will act as compression reinforcement. In the piles of these tests, when the compressive strain in the adjacent concrete exceeded about 0.006 , the tensile stress in the tendon was reduced to zero and hence at higher concrete compressive strains the tendon was in compression. For the nonprestressed longitudinal steel in Unit IF the stressstrain curve used followed closely the measured curve for that steel.

The approach for determining the theoretical moment-curvature relation was outlined in section 2.2. The M value listed in Table 2 was the maximum moment reached in the theoretical momentcurvature curve. It is evident from Table 2 that this refined moment-curvature analysis approach gives a much better prediction of the theoretical flexural strength.

Fig. 19 shows two examples of the theoretical moment-curvature relations compared with the measured points at the peaks of the loading cycles. The theoretical moment-curvature predictions were conservative, mainly due to the conservative nature of the Park-Leslie stress-strain curve for spirally confined concrete, particularly at large deformations. As expected, the well confined Unit $2 \mathrm{~F}$ exhibits reasonable ductility, but the poorly confined Unit $4 \mathrm{~F}$ behaved in a brittle manner.

5. CONCLUSIONS

1. The tests indicated that the presence of nonprestressed longitudinal reinforcement in prestressed concrete piles is not essential to the satisfactory ductile performance of the piles. Nonprestressed longitudinal reinforcement need only be present if required for anchorage of the pile end.

2. Prestressed concrete piles designed to the New Zealand concrete design code provisions for spiral confining reinforcement, as though they were columns, exhibited stable Is teral loaddisplacement hysteresis loops at displacement ductility factors in excess of $\mu= \pm 8$. However, it is recommended that the amount of spiral confining steel be based on an effective axial load that is the sum of the internal prestress force and the maximum externally applied load. 


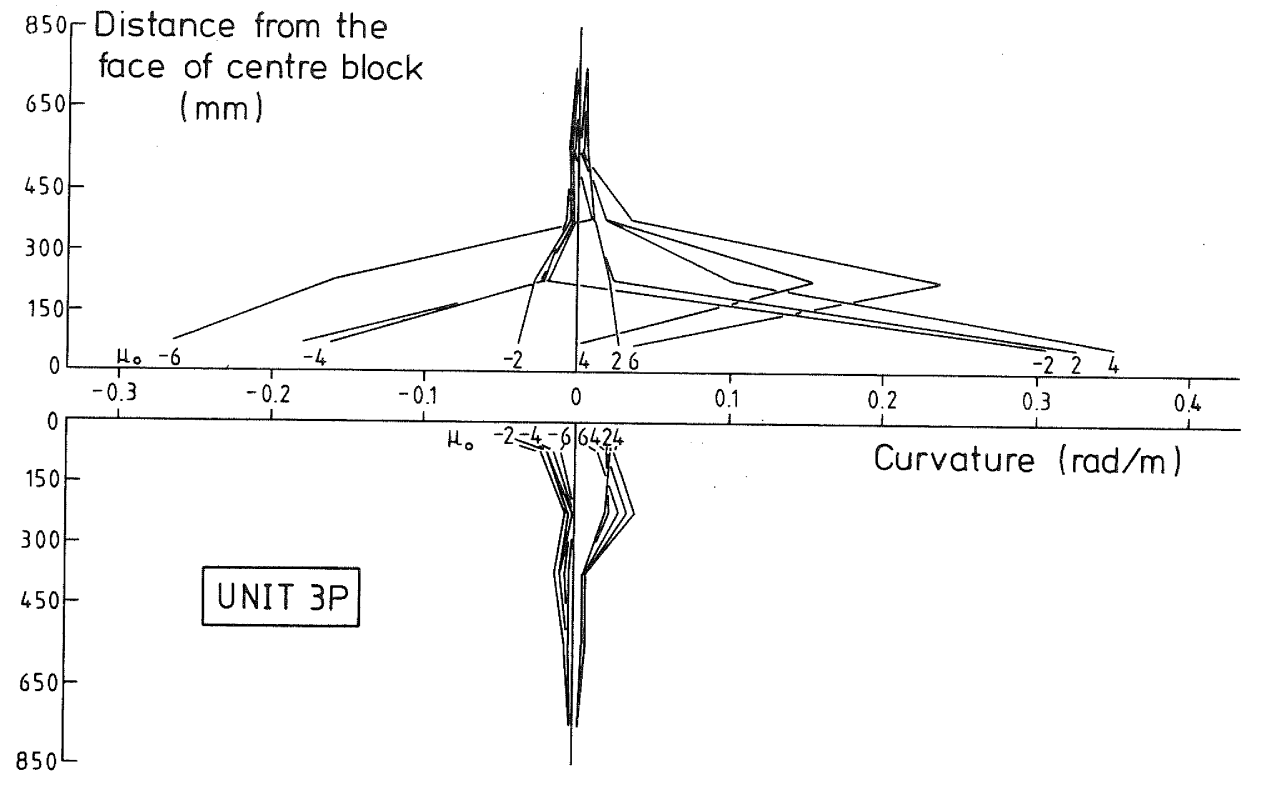

Fig. 16 Curvature Distribution for Unit 3P

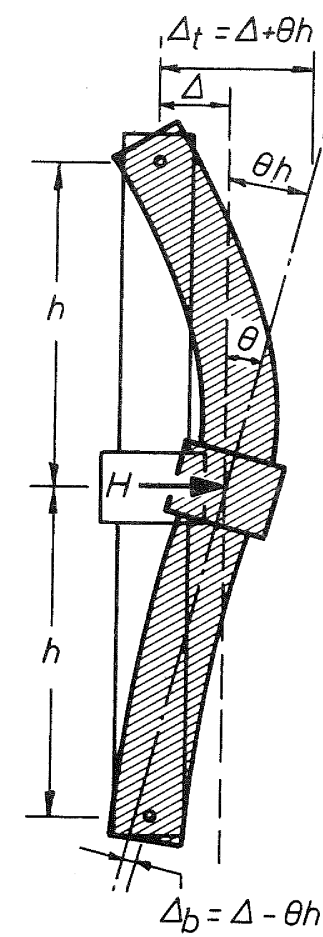

Fig. 17 Implication of Rotation $\theta$ of Centre stub During Testing

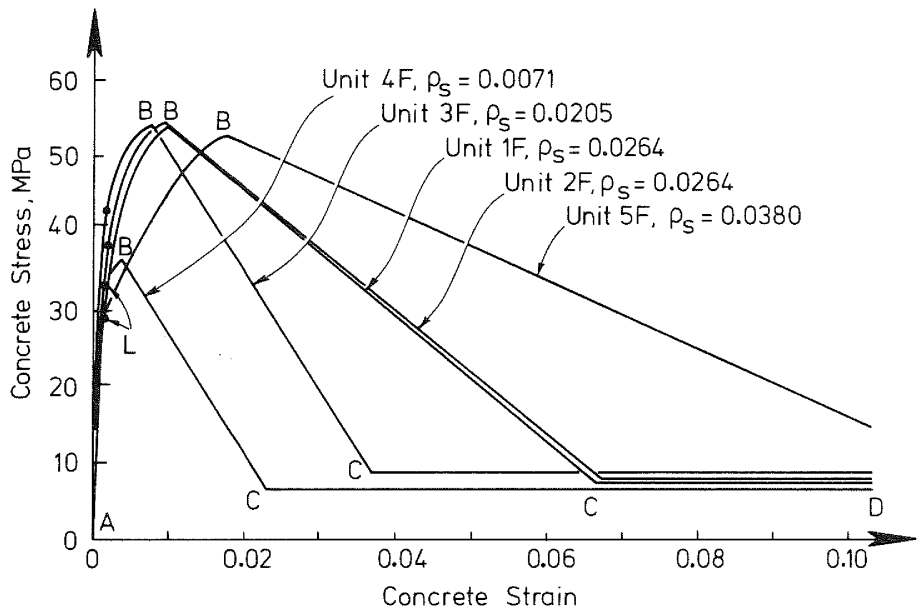

(a) Confined concrete using Park-Leslie stress-strain curve

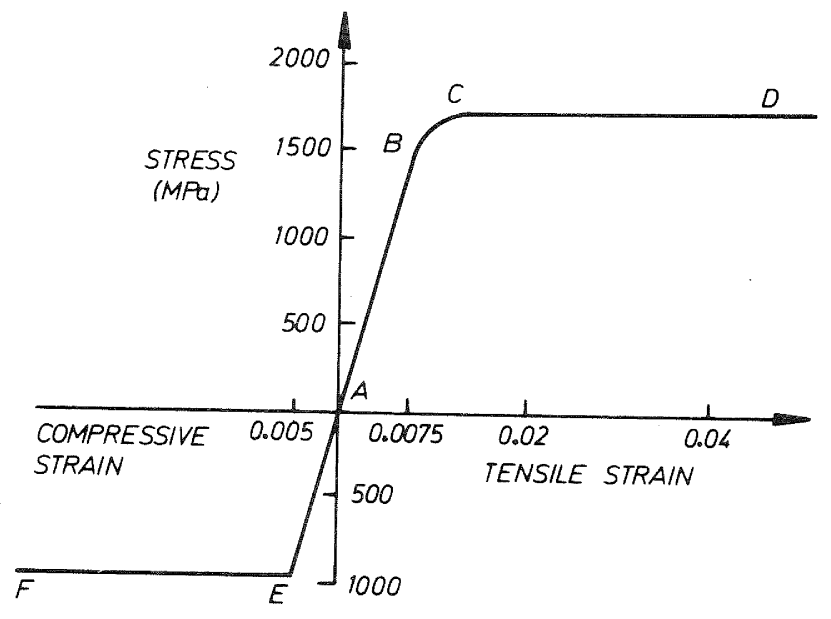

(b) Prestressing steel

Fig. 18 Assumed Stress-Strain Curves for Moment-Curvature Analysis of Units $1 F$ to $5 F$ 
3. Prestressed concrete piles with between 24 and 50\% of the code amount of spiral confining steel, so calculated, failed at maximum displacement ductility factors between 2.5 and 7 . When the spiral reinforcement was provided by hard drawn wire, the response was limited by the eventual fracture of the confining steel, whereas piles confined by Grade 275 steel spirals did not suffer confining steel fracture.

4. All of the partially confined piles suffered compression buckling of the prestressing strand at displacement ductilities of about $\mu= \pm 4$, despite a spiral pitch that was less than one fifth of the pile diameter and less than six times the diameter of the prestressing strand in all but one pile. Restraint against buckling of the individual strands may be difficult to provide, but it was noticeable that piles with a spiral pitch of either $35 \mathrm{~mm}$ or $45 \mathrm{~mm}$ did not suffer buckling of prestressing strands, despite high compression strains. Conservatively, and pending results of on-going research, it is recommended that the maximum pitch of confining steel for pretensioned piles be limited to $4 \mathrm{~d}$ where $d_{b}$ is the nominal diameter of ${ }^{b}$ the prestressing strand, regardless of the level of confinement provided.

5. It is believed that prestressed concrete piles confined with $50 \%$ of the code amount of spiral confining steel for an axial load level of $\left(0.3 f^{\prime}+f_{p}\right) A_{g^{\prime}}$
and with a spiral spacing not and with a spiral spacing not diameters or one-fifth of the pile diameter, will provide dependable displacement ductility of at least $\mu= \pm 4$, which should exceed any accidential ductility demand.

6. The theoretical flexural strengths calculated using the AC'I concrete compressive stress block, an extreme fibre concrete compression strain of 0.003 , and the measured material strengths, underestimated the maximum measured moment capacity of the pile units. The ratio of the measured maximum moment to this theoretical moment for the eleven piles ranged between 1.12 and 2.39 , indicating the considerable effect of the enhancement of concrete strength due to confinement on the flexural strength of the units. A refined moment-curvature analysis utilising a stress-strain curve for confined concrete resulted in much closer predictions of the flexural strength.

6.

\section{CONTINUING RESEARCH}

A further series of six prestressed concrete piles will be tested at the University of Canterbury in 1984 to give further information on partially confined piles with Grade 275 spiral steel, fully confined piles with hard drawn steel spirals (investigating particularly the stage of spiral steel fracture), and piles with spiral spacings in the order of 4 times the strand diameter to restrain buckling of the strand at high curvatures. In 1985 . tests will also be conducted on prestressed pile-pile cap connections to investigate different methods for achieving anchorage of the pile in the pile cap and the effect of having the critical section for pile flexure probably within the end transfer length of the prestressing strand.

\section{ACKNOWLEDGEMENTS}

The work described was carried out with generous financial assistance provided by the National Roads Board of New Zealand and the University of canterbury. The detailed work was carried out by T.J. Falconer and Pam Hoat Joen as part of their Master of Engineering studies under the supervision of $\mathrm{R}$. Park. The cooperation shown by Stresscrete (Canterbury) Itd and Precision Precasting Ltd, Christchurch, in allowing the use of their pretensioning beds, is gratefully acknowledged. The invaluable contributions of University of Canterbury staff, N.W. Prebble, G.E. Hill, P. Mitchell, G. Sim, L. Gardner, Valerie Grey and Alice Watt, are gratefully acknowledged.

\section{REFERENCES}

(1) Sheppard, D.A., "Seismic Design of Prestressed Concrete Piling", Journal of the Prestressed Concrete Institute, Vol. 28, No. 2, March-April 1983, pp. $20-49$.

(2) Gerwick, Ben C. Jr., "Seismic Design of Prestressed Concrete Piles", Proceedings of the 9 th congress of the Fédération Internationale de la Précontrainte, Volume 2, Stockholm, 1982, pp. 60-69.

(3) Park, R. and Paulay, T., "Reinforced Concrete Structures" John Wiley and Sons, New York, 1975, 769p.

(4) New Zealand Standard Code of Practice for the Design of Concrete Structures, NZS 3101, Part 1:1982, Standards Association of New Zealand, Wellington $1982,127 \mathrm{p}$. (Commentary: NZS 3101, Part 2: 1982, 156pp).

(5) Falconer, T.J. and Park, R., "Ductility of Prestressed Concrete Piles Under Seismic Loading", Research Report 82-6, Department of Civil Engineering, University of Canterbury, February $1982,121 \mathrm{p}$.

(6) Park, R. and Falconer, T.J., "Ductility of Prestressed Concrete Piles subjected to Simulated Seismic Loading", Journal of the Prestressed Concrete Institute, Vol. 28, No. 5, September-October 1983, pp. 112-144.

(7) Pam Hoat Joen, and Park, R., "Ductility of Prestressed Concrete Piles Subjected to Simulated Seismic Loading", 
Research Report No. 84-4, Department of Civil Engineering, University of Canterbury, February 1984, 170p.

(8) Mander, J.B., Priestley, M.J.N. and Park, R." "Seismic Design of Bridge Piers", Research Report No. 84-2, Department of Civil Engineering, University of Canterbury, February $1984,442 \mathrm{p}$ plus appendices.

(9) Park, R. and Leslie, P.D., "Curvature Ductility of Circular Reinforced Concrete Columns Confined by the ACI Spiral", 6th Australasian Conference on the Mechanics of Structures and Materials, Vol. 1, Christchurch, August 1977, pp.342-349.

(10) Thompson, K.J. and Park, R., "Ductility of Prestressed and Partially Prestressed Beam Sections", Journal of the Prestressed Concrete Institute, Vol. 25, No. 2, March-April 1980, pp. $46-70$.

(11) Seismology Committee, "Recommended Lateral Force Requirements and Commentary", Structural Engineers' Association of California, 1975, 21p. plus appendices.

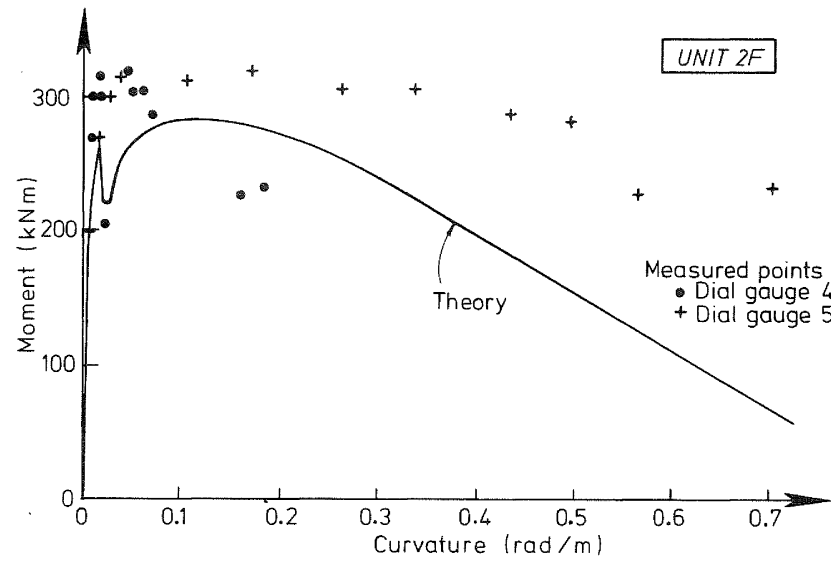

(a) Unit $2 \mathrm{~F}$

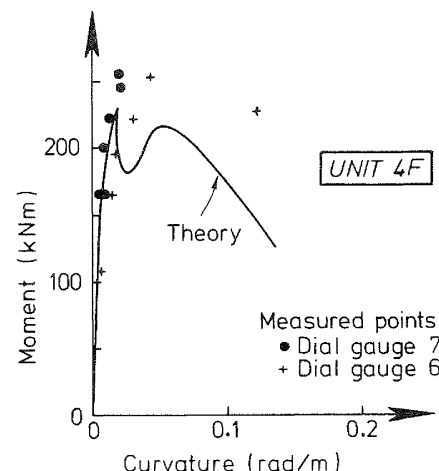

(b) Unit $4 \mathrm{~F}$ 